\author{
WALDEN \\ UNIVERSITY \\ A higher degree. A higher purpose.
}

Walden University ScholarWorks

Walden Dissertations and Doctoral Studies

2016

\title{
Evaluation of Low Immunization Coverage Among the Amish Population in Rural Ohio
}

Christine Marie Kettunen

Walden University

Follow this and additional works at: https://scholarworks.waldenu.edu/dissertations

Part of the Public Health Education and Promotion Commons

This Dissertation is brought to you for free and open access by the Walden Dissertations and Doctoral Studies Collection at ScholarWorks. It has been accepted for inclusion in Walden Dissertations and Doctoral Studies by an authorized administrator of ScholarWorks. For more information, please contact ScholarWorks@waldenu.edu. 


\title{
Walden University
}

\author{
College of Health Sciences
}

This is to certify that the doctoral dissertation by

\author{
Christine Kettunen
}

has been found to be complete and satisfactory in all respects, and that any and all revisions required by the review committee have been made.

Review Committee

Dr. John Nemecek, Committee Chairperson, Public Health Faculty

Dr. Chester Jones, Committee Member, Public Health Faculty Dr. Daniel Okenu, University Reviewer, Public Health Faculty

Chief Academic Officer

Eric Riedel, Ph.D.

Walden University

2016 


\begin{abstract}
Evaluation of Low Immunization Coverage Among the Amish Population in Rural Ohio by

Christine Kettunen
\end{abstract}

MSN, Capital University, 1999

BSN, Capital University, 1992

\author{
Dissertation Submitted in Partial Fulfillment \\ of the Requirements for the Degree of \\ Doctor of Philosophy \\ Public Health
}

Walden University

May, 2016 


\begin{abstract}
Amish communities have persistently low childhood immunization rates. Prior to this study, reasons for low rates had not been clearly identified. Researchers have speculated that access to health care, religious factors, and fear might be reasons that Amish parents refuse childhood immunizations, but more empirical evidence was warranted.The purpose of this study was to gather that empirical evidence regarding the knowledge, attitudes, opinions, and beliefs of Amish parents residing in Ashtabula County Ohio, an additional purpose was to examine how these factors influence timely immunizations of Amish children. The theoretical framework was the PEN-3-Cultural Model, focusing on cultural influences, beliefs, and experiences in health behavior of individuals in a community. The development of a 20 question survey was guided by 4 research questions designed to evaluate any differences in Amish parents' decision to defer recommended childhood immunizations. Multivariate analysis of variance was used to evaluate the 4 research questions based on the 84 individual surveys received. Results revealed a significant link between knowledge, beliefs, and opinions toward immunization and immunization adherence. Results also revealed that age and gender had no effect on the relationship between knowledge, beliefs, attitudes, and opinions toward immunization adherence. This study contributes to positive social change by educating parents of Amish children as to why it is important to receive timely childhood immunizations; thereby, keeping their children safe from vaccine-preventable diseases.
\end{abstract}


Evaluation of Low Immunization Coverage Among the Amish Population in Rural Ohio

by

Christine Kettunen

MSN, Capital University, 1999

BSN, Capital University, 1992

\author{
Dissertation Submitted in Partial Fulfillment \\ of the Requirements for the Degree of \\ Doctor of Philosophy \\ Public Health
}

Walden University

May, 2016 


\section{Dedication}

This work is dedicated in memory of my father, Emerson J. Thompson who believed in the value of education and inspired me to advance mine. 


\section{Acknowledgments}

I wish to acknowledge that the completion of this doctoral dissertation was possible with the support of God and several individuals. I wish to express my sincere thanks to all of them. First of all, I would like to thank God for giving me the wisdom and ability to complete this dissertation. I would next like to thank my committee chair, Dr. John Nemecek for his suggestions, guidance and support throughout this process. I am grateful for his invaluable encouragement during all stages of the dissertation process. I would also like to thank my other committee member, Dr. Chester Jones for his valuable input and insightful comments. I would like to thank the University Research Reviewer Dr. Dan Okenu for providing the constructive criticisms necessary to improve the quality of my work. I am grateful to my employer, The Ashtabula County Board of Health, Paul Thompson FNP, Kathleen Arilson, RN, Thomas Hunt, DO, Harold Asbury, Jaime Cordova, and Gary Hewitt, my colleagues Ray Saporito MPH, Dr. Robert Malinowski, and Louie Donathan for approving the study and for their encouragement during the process. I would also like to thank the health department's nursing division members Barb Distelrath RN, Mary Verzumo BS RN, Michelle Pitkin BSN, RN, Valerie McDowell RN, Tammy Mathews RN, Andrea Plaskett MPH, April Tredway LPN, Carol Koivisto, and Autumn Snyder who supported my effort. Most importantly, I owe my deepest gratitude to members of my family. I am indebted to my husband, Alan Kettunen, who provided a constant source of strength and inspiration for me throughout this process. To my sons, James and Michael, and my daughter Michelle, my sister Marti and my brother Dale who supported this effort, my thanks and love. I want to thank my 
mother, Ruth Thompson, for her love, constant prayers and continued support. I want to thank my grandchildren Katie, Jesse, Brendon, my nieces, Abbey, Aubrey, and Jasper, my nephews, Andrew, Jeremy, Ian, Mason, Shawn, Michael, my godson Jonathan and dear friend Bernice for reminding me of my blessings during the difficult times of the dissertation process. I owe my achievements to my family. 


\section{Table of Contents}

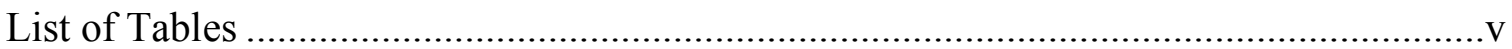

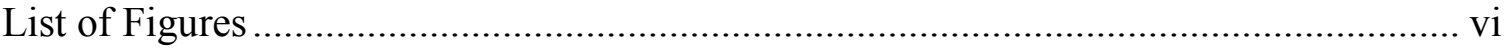

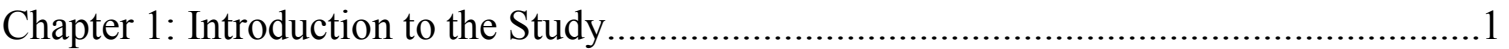

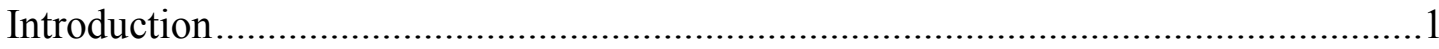

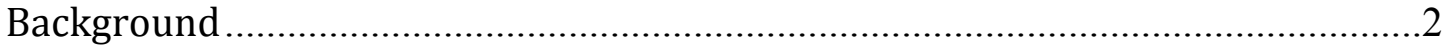

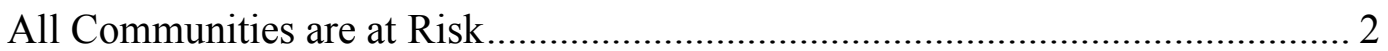

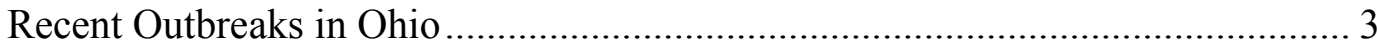

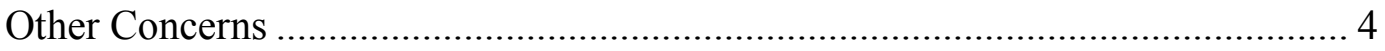

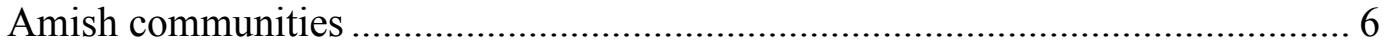

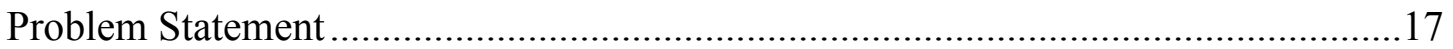

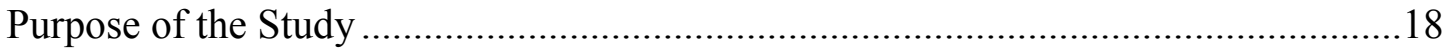

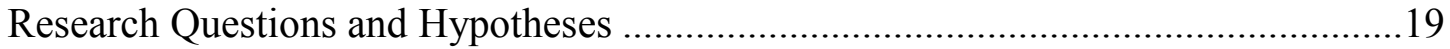

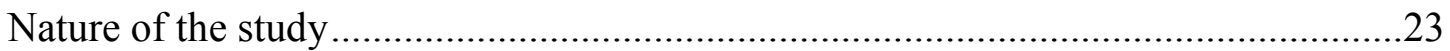

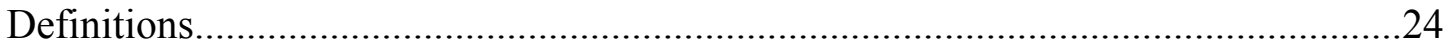

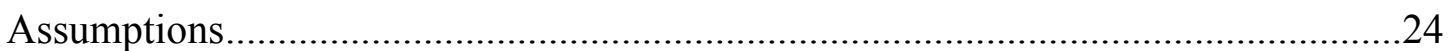

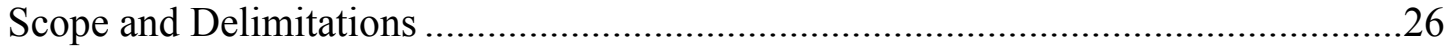

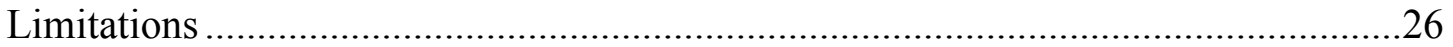

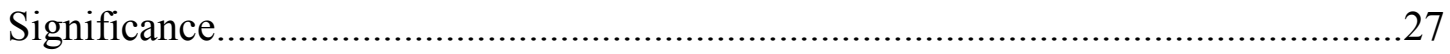

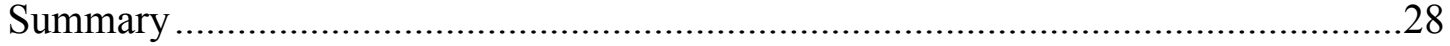

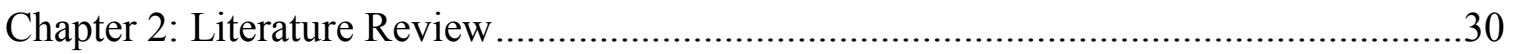

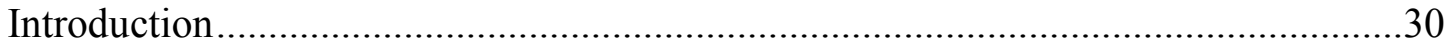




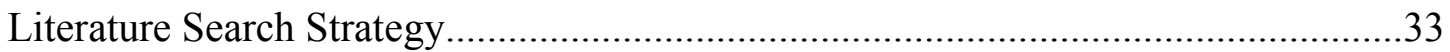

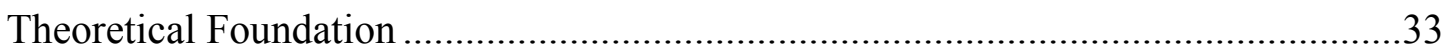

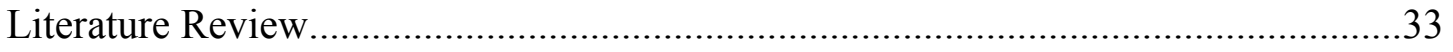

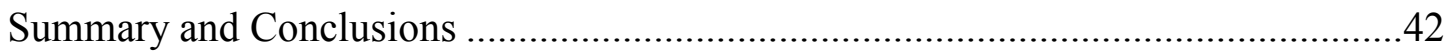

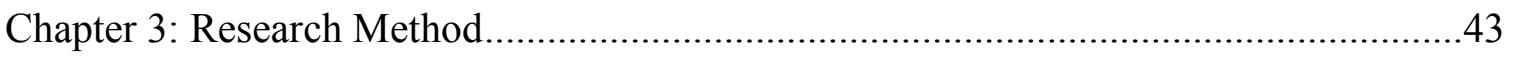

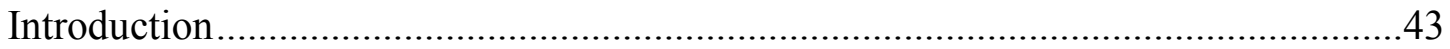

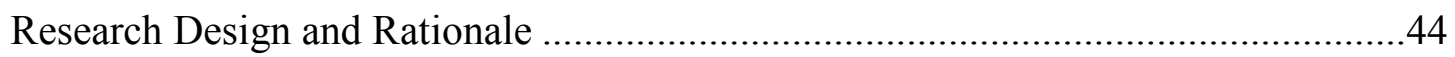

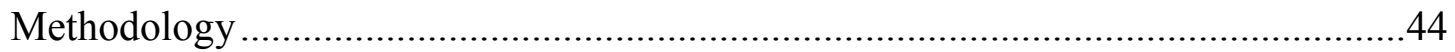

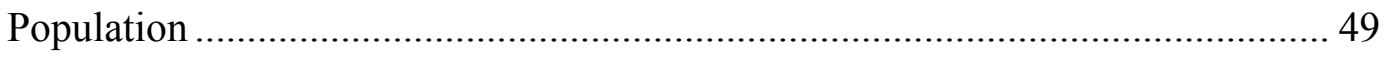

Sampling and Sampling Procedures ………………....................................... 49

Procedures for Recruitment, Participation, and Data Collection ........................... 50

Instrumentation and Operationalization of Constructs ....................................... 51

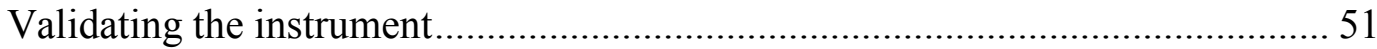

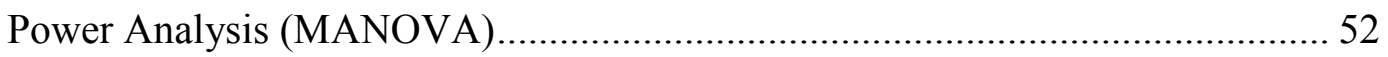

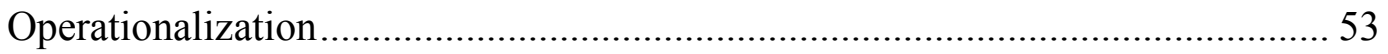

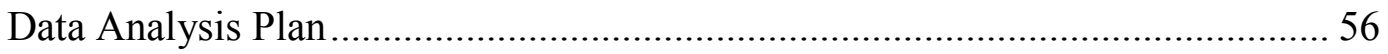

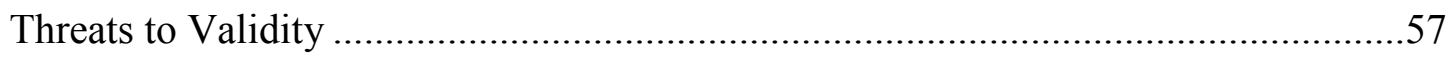

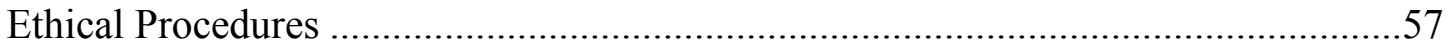

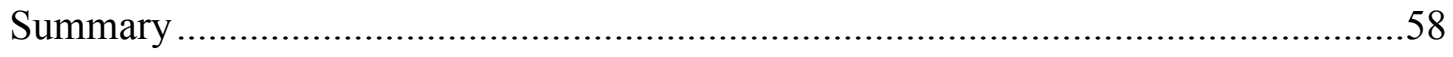

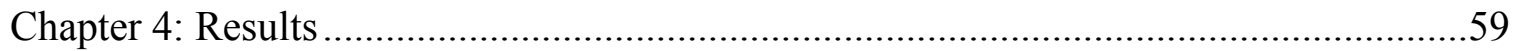

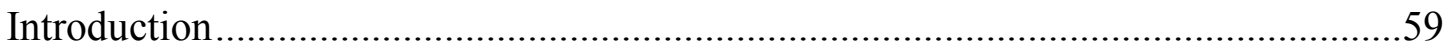

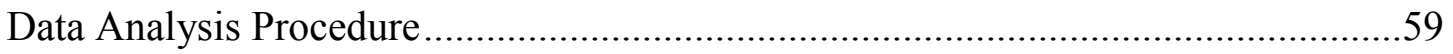




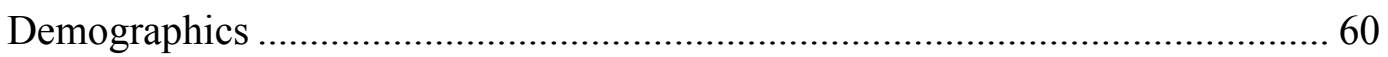

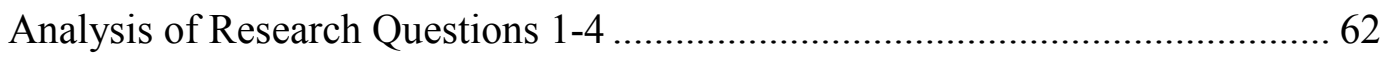

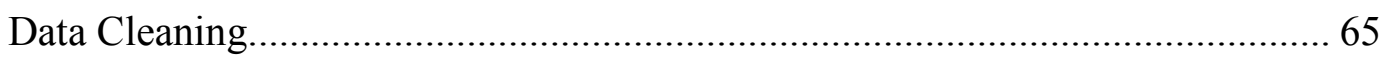

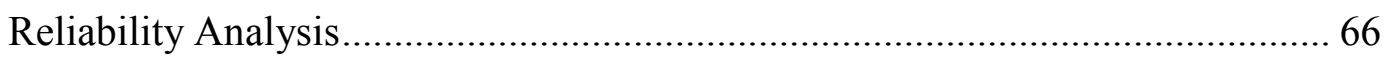

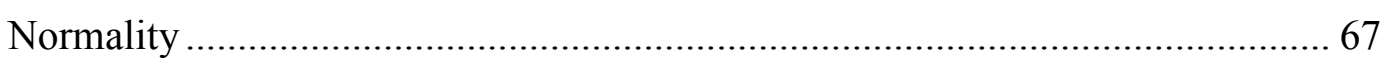

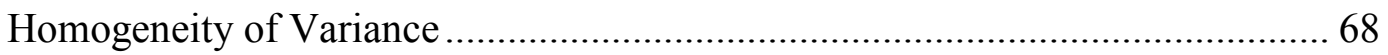

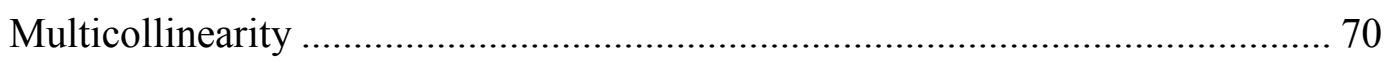

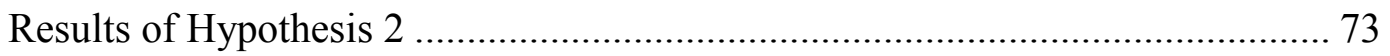

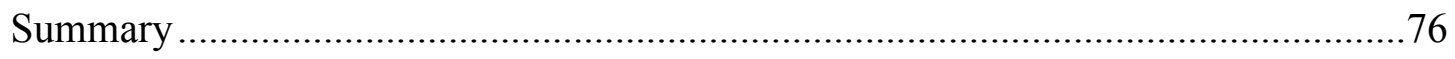

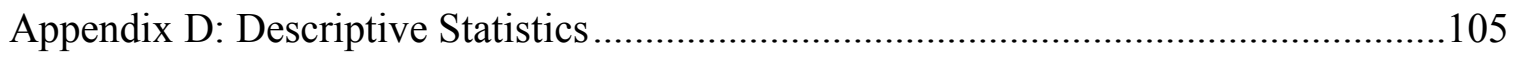

Chapter 5: Discussion, Conclusions, and Recommendations .............................................77

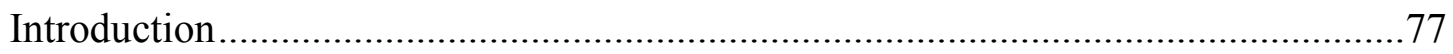

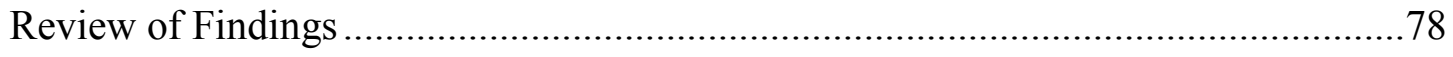

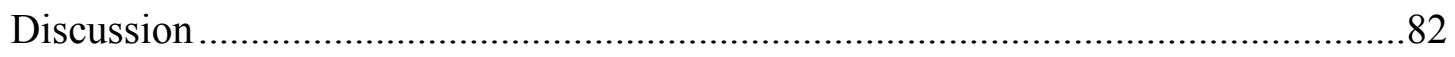

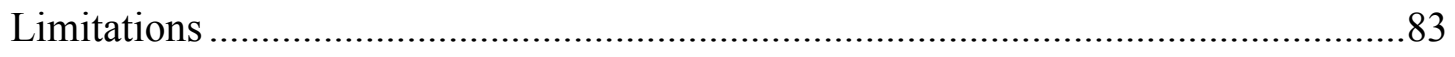

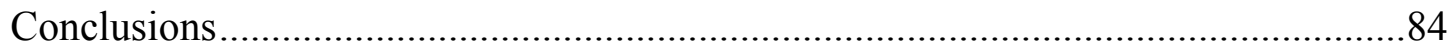

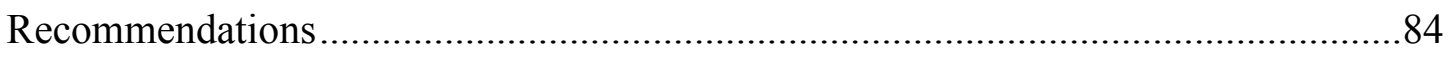

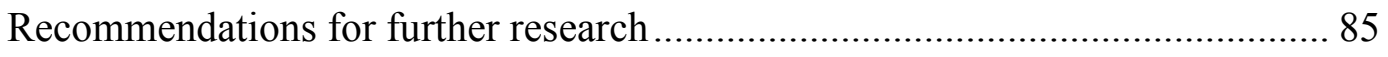

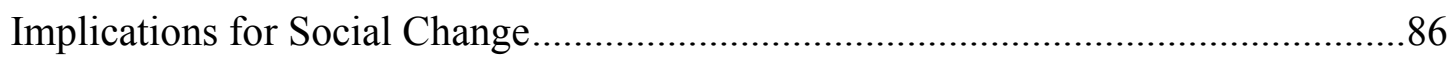

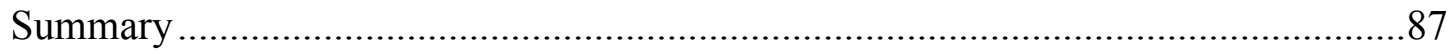

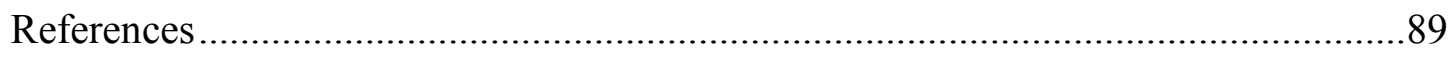

Appendix A: Amish Immunization Questionnaire ……….........................................94 
Appendix B: 2014 CDC Recommended Immunization Schedule...............................103

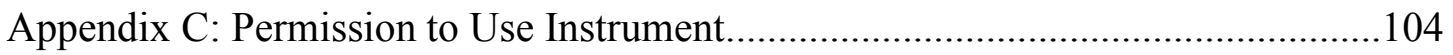

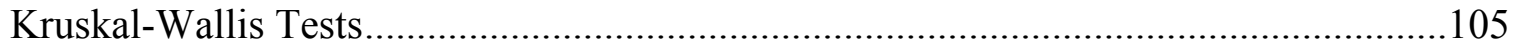




\section{List of Tables}

Table 1. Variables and corresponding Survey Information..........................57

Table 2. Variables and Statistical Tests Used to Evaluate Research Questions 1-4......61

Table 3. Frequency and Percent Statistics of Participants Gender, Age, Group, and Whether Parents Provided their Children with all Recommended Immunizations

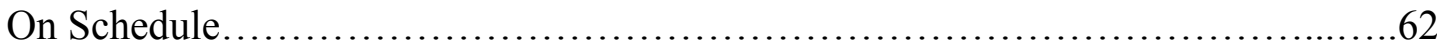

Table 4. Descriptive Statistics of Participants' Knowledge, Beliefs, Attitudes, and Opinions of Childhood Immunization by Whether They Provided Immunizations on Schedule.

Table 5. Summary of Reliability Analysis for the Dependent Variables used to Evaluate

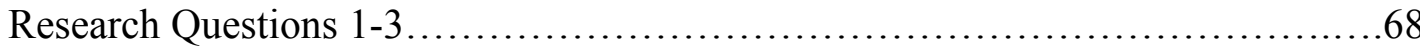

Table 6. Skewness and Kurtosis of Statistics of Participants' Knowledge, Beliefs, Attitudes, and Opinions of Childhood Immunization by Whether Parents

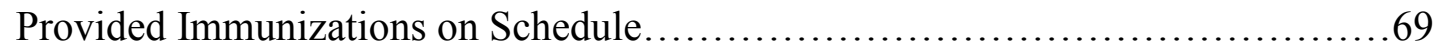

Table 7. Summary of Levene's Test for Research Questions 1-3.....................70

Table 8. Summary of Box's M Tests Conducted for Research Questions 1-3...........71

Table 9. Correlations Between Dependent Variables................................72

Table 10. Summary of MANOVA Multivariate Analysis for Hypothesis 1 .............73

Table 11. Model Summary of Between Subjects Effects for Research Question 1......74

Table 12. Summary of MANOVA Multivariate Analysis for Hypothesis 2 ..............76

Table 13. Summary of MANOVA Multivariate Analysis for Hypothesis 3.............77 


\section{List of Figures}

Figure 1. Theoretical Model of the Variables Under-Study.......................47

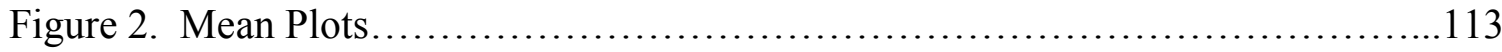


Chapter 1: Introduction to the Study

\section{Introduction}

Vaccine-preventable disease has been at the forefront of public health initiatives in the United States for several decades. In 1999, the Centers for Disease Control and Prevention (CDC) acknowledged the success of these measures by proclaiming vaccine development and usage as one of the top 10 public health achievements of the $20^{\text {th }}$ century. Despite this acknowledged success, childhood immunization rates are much lower in select populations (Healthy People 2020, 2014). This study examines one of those populations, the Amish community in Ashtabula County, Ohio.

The Recommended Childhood Vaccine Schedule is published annually by the Advisory Committee on Immunization Practices (ACIP), a U.S.-based group of experts who develop vaccine recommendations. The recommendations made by ACIP are endorsed by the American Academy of Pediatrics (AAP), the American Academy of Family Practitioners (AAFP), and the Pediatric Infectious Disease Society (PIDS). The 2014 United States vaccination schedule recommends up to 54 doses of vaccine to protect against 16 diseases by the time an individual reaches 18 years old. Twenty-eight doses of vaccine are recommended for children before they reach the age of 2 years. Depending on the use of combination vaccines the number of doses a child receives is normally less than 28 (CDC, 2014). The 2014 vaccination schedule can be seen in Appendix B of this study.

The goal set by Health People 2020 is to increase the childhood immunization rate to $90 \%$ or greater. Researchers have indicated although immunization rates have 
increased during the last twenty years, coverage is still only approximately $77 \%$ nationwide (Healthy People 2020, 2013). Recent researchers have shown immunization rates for diseases such as measles have decreased over the past five years. In 2014, more cases of measles were reported in the United States than had been reported in the previous decade (CDC, 2014).

\section{Background}

\section{All Communities are at Risk}

When parents decide not to immunize a child, it creates risk of disease for the unimmunized child, as well as others who may come in contact with the unimmunized child. Contracting a vaccine preventable disease can be dangerous or may even cause death. One out of 30 children who contract measles develops pneumonia. For every 1,000 children who get measles, one or two die from the disease (CDC, 2014).

In 2008, a seven year-old unvaccinated child returned home from a family vacation in Switzerland. He developed a cough and runny nose nine days later. His parents thought he had a cold and sent him to school. The child's condition continued to worsen and his mother took him to the physician's office the next day. The child was eventually diagnosed with measles (CDC, 2008). Prior to his diagnosis, he exposed several children to the disease including his unvaccinated siblings, classmates, and children in the physician's office. Three of these children were too young to have received the Measles, Mumps, and Rubella (MMR) vaccine. The child's siblings became ill along with several of his classmates. Additionally, all three of the children who were 
exposed in the physician's office developed measles and one child was hospitalized with a severe case of the disease (CDC, 2008).

There are children who are unable to be vaccinated for medical reasons. The MMR vaccine is a live vaccine, and according to ACIP guidelines, should not be given to individuals with an underlying immunosuppressive disorder. Children with some forms of cancer, such as Leukemia, would not be eligible to receive the MMR vaccine. A child who is unvaccinated and has an immunosuppressive condition is at extremely high risk for developing measles if exposed to someone with the disease. Measles in an immunocompromised individual can be severe, and even result in death (CDC, 2008.)

Measles is highly contagious three to four days before the rash develops. Initially the symptoms are similar to a cold or upper respiratory disease. Measles is transmitted through respiratory droplets in the air; therefore, when an individual with the disease coughs, sneezes, or speaks, particles can be suspended in the air for another individual to breath in (CDC, 2014).

\section{Recent Outbreaks in Ohio}

The Ohio Department of Health (ODH) with assistance from the CDC, the Holmes County Health Department, and the Knox County Health Department, began investigating a measles outbreak in Holmes and Knox counties in April 2014. A group of Amish individuals traveled to the Philippines in March on a mission trip. Two unvaccinated individuals became seriously ill shortly after returning from the trip. The CDC confirmed a diagnosis of measles. As of September 25, 2014, the number of 
measles cases confirmed in Holmes and Knox Counties was 368. The total number of cases in the United States increased to 592, as of September 25, 2014.

The Holmes County Health Department estimates there are thousands of unvaccinated Amish children in the community. Almost every unvaccinated individual who comes in contact with measles has the potential to develop infection. Measles can be deadly, especially in infants and young children. Amish families of those who had measles cooperated and were willing to get their children vaccinated. Those who contracted measles followed recommendations for quarantine as recommended by the state and local health departments.

Approximately one-third of individuals infected with measles develop complications. Pregnant women are at risk because measles can cause premature delivery or miscarriage $(\mathrm{ODH}, 2014)$. Prior to this outbreak, there had not been a confirmed case of measles in Ohio in over 15 years. In the United States, measles had been virtually eradicated in 2000; however, public health officials have noted an increase in imported cases related to overseas travel over the past decade. Similar to the outbreak in Knox and Holmes Counties, most measles outbreaks in the United States continue to originate after an unvaccinated person travels out of the country and contracts the disease. When they return to the United States, they can infect other unvaccinated individuals (ODH, 2014).

\section{Other Concerns}

Measles is a single example of a vaccine preventable disease of concern among public health officials. A small outbreak of Haemophilus influenza Type B (Hib) was 
reported in Minnesota in 2008. Five children between the ages of 5 months and 3 years of age developed $H i b$ disease, and one of these children died. A vaccine to prevent $H i b$ had been available for approximately 20 years; however, the parents of these affected children refused or deferred the vaccine (CDC, 2009).

In addition to the Minnesota outbreak in 2008 and 2009, outbreaks of Hib meningitis occurred in Pennsylvania, New York, Maine, and Oklahoma. These outbreaks resulted in the death of four more children, and several more children became ill with the disease. The parents of the children in these cases had made the choice not to vaccinate their children. Before the $H i b$ vaccine was available $H i b$ caused meningitis, pneumonia, and serious bloodstream infections in approximately 20,000 children each year. Approximately 1000 individuals died from the disease each year, and many others were left with permanent brain damage. An increase in the number of other vaccine preventable diseases has been noted in the past decade (CDC, 2013).

Communities with low rates of immunization are particularly at risk for outbreaks of vaccine preventable diseases. Many researchers have examined outbreaks among communities with low immunization rates similar to the Ohio Measles outbreak (MedinaMarion et al., 2013). Many of the findings have been similar and are generally related to parents refusing immunization of their children based on common factors that will be discussed in this study. 


\section{Amish communities}

Amish Communities are often recognized as having a lower rate of immunization coverage when compared with nearby non-Amish communities (Wenger, McManus, Bower \& Langkemp, 2011).

There is insufficient information regarding the knowledge, beliefs, attitudes, and opinions, among Amish parents that may influence their decisions to immunize their children. Previous Researchers have implied reasons may vary among Amish communities (Wenger, et al., 2011).

Amish individuals travel outside of their communities and can place others at risk for contracting vaccine preventable diseases if they are not vaccinated. Amish do not drive automobiles; however, they hire drivers to take them to stores, malls, county fairs, and other places where large groups of people gather. Amish individuals rarely take vacations, but do travel to other settlements and often stop at scenic sites where they have contact with other individuals outside of the Amish community. Many Amish individuals travel by train or bus or chartered vans. Traveling together with family, friends, and extended kin help to bond and build their community life (Ohio State University [OSU], 2011). This study will focus specifically on the Amish population in Ashtabula County, Ohio, with the intent of determining reasons for the lower rate of immunization coverage among the Amish.

Globally vaccines are viewed as a cost-effective method to prevent disease and death (CDC, 2000). Childhood immunization has proven to be a vital component of health promotion. Statistics reported in the year 2000 indicated the United States had 
achieved the lowest rates of vaccine preventable diseases and the highest rates of immunization ever recorded (CDC, 2000). In the past five years the United States had recognized an increase in the numbers of certain vaccine preventable diseases, and a decrease in rates of certain immunizations. Multiple outbreaks of vaccine preventable diseases including pertussis, rubella, measles, varicella, and $H i b$ have been reported in under-immunized Amish communities (CDC, 2006). Understanding select populations, such as the Amish, is crucial for prevention of disease outbreaks because underimmunized populations are suspected of being reservoirs for infection.

\section{History of the Amish}

Understanding the Amish culture is important in order to provide appropriate health care for this culturally diverse group. It is important to understand the background of this Amish society if healthcare concerns including the important of immunizations are to be addressed with this group (Weyer et al., 2003).

The Amish are a group of traditionalist Christian church fellowships. The root of the Amish community comes from the Mennonite community. The Amish and the Mennonites were part of the early Anabaptist movement that took place in Europe at the time of the reformation. Anabaptists believed only adults who had confessed their faith should be baptized. Menno Simons, a catholic priest from Holland joined the Anabaptist movement in 1536. His leadership united many of the Anabaptist groups who were called Mennonites. In 1693, Jakob Amman, a Swiss bishop, broke away from the Mennonite church. The Amish church originally began in Switzerland in 1693 when this group of Swiss and Alsatian Anabaptists led by Jakob Ammann became known as the Amish. 
During this time, many Anabaptists were put to death by both Catholic and Protestants for this belief, and many fled to the mountains of southern Germany and Switzerland. Many Amish immigrated to Pennsylvania in the early $18^{\text {th }}$ century as part of William Penn's holy experiment of religious tolerance (Amish Studies, 2014).

The first group of Amish came to Lancaster County Pennsylvania in the 1720s Three groups of Anabaptists developed and continue to remain in Lancaster County, including (a) the Amish, (b) Mennonites, and (c) Brethren. All share the Anabaptist belief that individuals must make a conscious choice to accept God and accordingly only adults who make this choice are baptized. All of these three groups share the same basic values regarding the all-encompassing authority of the Bible. The groups primarily differ in matters of dress, forms of worships, language, and the extent to which they permit modern technology and the influences of the outside world to impact their lives. Over time the Amish began to settle in other states. Currently approximately 281,700 Amish reside in 30 states in the United States. Ohio has the largest concentration of Amish followed by Pennsylvania and Indiana. Sixty-four percent of the Amish live in one of these three states. Ohio is home to 65,475 Amish, Pennsylvania is home to 65,270 Amish, and Indiana is home to 49,070 Amish (Amish Studies, 2014).

The population of the Amish in the United States in 2001 was reported to be approximately 200,000(Amish Studies, 2014). This number has increased significantly over the past decade and it is expected to continue to increase. The Amish population has doubled over the past 20 years because most families have five or more children on 
average. The first Amish settlers moved into Ohio from Somerset County Pennsylvania in 1808 (Amish Studies, 2014).

It is estimated there are currently 65,475 Amish residing in Ohio and over 450 Amish church districts in the state. Holmes County has the largest population of Amish in Ohio with 227 church districts and approximately 20,000 people. The second largest Amish population in Ohio is located in Geauga County. There are approximately 12,000 Amish individuals who live in Geauga County. Ashtabula County is located adjacent to Geauga County and the Geauga Amish settlement stretches into both Ashtabula and Trumbull Counties. There are approximately 3,000 Amish individual residing in Ashtabula County (Amish Studies, 2014).

The Amish churches have divided many times over the years due to doctrinal disputes. There are different orders of Amish; however, basic religious beliefs are the same among these orders. These Amish religious basics help define what it means to be Amish. There is not a single governing body for the entire Amish population; each church district decides what it will, and will not accept. All church districts base their regulation on literal interpretation of the Bible and a set of rules known as the Ordnung. Amish individuals are discouraged from personal Bible study and devotions because individual interpretations may challenge the traditional doctrine of the specific order to which the individual belongs. Amish life is dictated by the certain oral and written rules of the Ordnung. The Ordnung can dictate aspects of Amish lifestyle such as the way they dress, length of hair, buggy style and farming techniques. The Ordnung varies from community to community and order to order. There are four orders that comprise Ohio's 
Amish. These are the Swartzentruber Amish, the Andy Weaver Amish, the Old Order Amish, and the New Order Amish. All four of these orders have a different Ordnung that dictates what they can, and cannot do. The greatest difference among the Amish orders is in relation to the use of technology (OSU, 2012).

The Swartzentruber and Andy Weaver Amish orders are ultraconservative in the use of technology. The Swartzentruber are the most conservative of the Amish. The Swartzentruber do not even permit the use of battery lights or ride in automobiles. The Swartzentruber Amish originated in 1913 due to a division in Holmes County. This is where they have their largest population today. This order resists change and have only adapted to modern conveniences slowly. Their homes lack indoor plumbing and they use outhouses. The new Order Amish are a subgroup of the old order Amish. This group split from the Old Order Amish church in the 1960s. Like the old order group, the new order Amish use horse and buggy for transportation, wear plain clothing, speak Pennsylvania German dialect, and practice worshiping at home. They also practice technological restrictions including prohibition of television and radios. Some new order Amish groups permit electricity around the home, especially in barns and other out building used for work. Some of these newer groups also permit telephones around their homes as well. Many have the phones located in their barns, or in the entrance way into the home. There are some of the newer order groups that permit cell phones (OSU, 2011).

The Amish supported public education when it revolved around one-room schools in the first half of the 20th century. The one-room schoolhouses posed little threat to Amish values since these schools were operated under local control. Clashes between the 
Amish and local and state officials occurred during the middle of the 20th century when massive consolidation of public schools started to occur, and there was pressure to require all students to attend high school. Formal education beyond the eighth grade is contrary to the beliefs of the Amish. This resulted in battles between the Amish and several individual states until the Supreme Court ultimately resolved the issue. The Supreme Court decision was the result of a case that started in Wisconsin. Three Amish families sued the state of Wisconsin because of a requirement that children be enrolled in school until they reach the age of sixteen (Wisconsin v. Yoder, 1972) The Supreme Court ruled in 1972, the First and Fourteenth Amendments in the constitution prevent the state from compelling children to attend formal education beyond the eighth grade. The Amish attempt to avoid conflict and try to avoid legal action; however, some of them do take a stand when they believe the government is interfering with their religious practices (Wisconsin v. Yoder, 1972).

The Amish complete formal education through the eighth grade. Most Amish children attend school in one-or two room private school houses. Amish schoolteachers complete the eighth grade in an Amish school before they can teach. A local school board comprised of three to five Amish fathers oversees the Amish schools. This school board hires the teachers, approves the curriculum, oversees the budget, and supervises maintenance (Amish Studies, 2014). The Amish schools play a critical role in the preservation of Amish culture. The schools reinforce Amish values and promote practical skills to prepare students for success in the Amish community. Children learn to speak, read, and write English in Amish schools. At the end of their eighth grade education 
students have developed basic competency in English; however, it may be spoken with an accent. The Amish speak a dialect known as Pennsylvania German or Pennsylvania Dutch. This was originally a German dialect spoken by settlers in southeastern Pennsylvania. In Amish culture, this dialect has become a form of oral communication and is the language of work, family, friendship, play, and intimacy. Even Amish who live outside Pennsylvania speak this Pennsylvania German dialect (Amish Studies, 2014).

Although most Amish complete their education in their own private schools a few Amish children attend rural public schools in some states. Since most Amish children do not attend public schools, they are not subject to the immunization requirements to attend public schools (Amish Studies, 2014).

School immunization requirements have been a key success factor in prevention and control of vaccine preventable diseases in the United States. Although no constitutional right exists to either a religious or philosophical exemption to these immunization requirements, most states permit religious exemptions and several permit philosophical exemptions. Courts, for the most part, have upheld these exemptions. Laws requiring immunizations were first enacted to control epidemic diseases. They are currently also used to increase the coverage rate for immunizations important in protecting the public's health. School immunization requirements will continue to play a role in preventing disease through assuring high vaccination coverage. As long as the balance of protecting the health of the public is achieved by mandating these requirements, these laws can be expected to be upheld (Jacobson v. Massachusetts, 1905). There are requirements for children to receive a number of immunizations to 
attend public schools in Ohio; however, the state of Ohio is one of twenty states that permit child immunization exemptions for religious and personal/philosophical beliefs. Parents just need to sign a refusal form for immunizations and can check medical, religious, and/or philosophical reasons for this refusal. Amish children and other children who attend public schools can be exempted from immunizations for any of these reasons (ODH, 2014).

Amish culture and religion stresses the need for separation from the world. The Amish view self-denial as an important part of their lifestyle. Practices and products such as high school, automobiles, cameras, televisions, and self-propelled farm machinery are most often viewed as worldly; although, the definition of worldliness varies within and between Amish orders (Amish Studies, 2014).

The Amish hold a variety of social gatherings that bring members of the community together for fellowship. Quilting bees and barn raisings mix hard work and good will with fun. Biweekly worship services are held in different Amish homes. There are no church buildings or any type of formal religious education even in Amish schools. Each school day opens with a scripture reading and prayer, but beyond that religion is not formally taught in the schools. Religion is practiced in all aspects of Amish life. The Ordnung is the religious blueprint for expected behavior; although the Ordnung varies considerably from order to order (Amish Studies, 2014).

Amish weddings are a social gathering and place a big responsibility on the bride's family. Amish weddings are typically held on Tuesdays and Thursdays in the fall of the year after the harvest is completed. The wedding takes place in the home of the 
bride and most often involves two meals, singing, food, and a three hour service. The service is similar to an Amish worship service and there are no flowers, rings, or instrumental music. The entire community is invited to the wedding. Amish brides usually make their own wedding dresses from blue or purple material. The newly married couple often lives with the bride's family until the spring when the couple sets up housekeeping in their own home; Amish society is patriarchal, and men assume the leadership roles. Women are permitted to nominate men to serve in ministerial roles but are not permitted to hold any formal church roles. A bishop, two preachers, and a deacon share the leadership responsibilities in the Amish district. They do not receive any formal pay for their services. The bishop serves at the spiritual elder and officiates at baptisms, weddings, funerals, ordinations, communions, and membership meetings. Schoolteachers are generally women; however, the school board is comprised of only men. The husband is the spiritual leaders of the home, but wives have considerable freedom. An isolated housewife is very rarely found in Amish society. In some Amish orders, women have become entrepreneurs who operate small quilt stores, craft stores, and even food stores. Although the Amish society is patriarchal, in most cases the mother of the children has an equal role in making decisions about their children's medical care, including immunizations (Amish Studies, 2014).

Amish pay federal and state income taxes, sales taxes, real estate taxes, and personal property taxes. They are exempt from contributing to Social Security following years of court battles. The Amish object to government aid on the basis they believe the 
church should assume responsibility for the social welfare of its own members. Federal aid in the form of Social Security or Medicare would erode dependency on the church. .

Most Amish refuse to pay for, or accept life or health insurance. Amish who do not have health insurance must pay all medical expenses out of pocket. Many Amish orders have developed their own Amish Health medical fund in attempt to assure money is available if medical expenses arise that an individual family cannot pay for on their own. Mothers in some Amish communities travel to a local hospital for the birth of their children; however, they usually go home shortly after the baby is born. In many communities, babies are born at home or in a local birthing center with the assistance of a midwife (Amish Studies, 2014).

The Amish believe good health is a gift from God that results from hard work and strict obedience to the teachings in the Bible. For most Amish individual's illness is believed to be God's will. The Amish do not view illness in terms of symptoms, but as the inability to function in work. Most Amish individuals do not seek care from a health care professional. The Amish often use forms of alternative medicine. They receive care from chiropractors, homeopaths, reflexologists, and utilize faith healing (Amish Studies, 2014). These types of practitioners do not routinely support the use of immunizations. Many chiropractors advise their clients against immunizations. The International Chiropractor's Association does not acknowledge the benefits of vaccines and opposes any mandatory requirements for immunizations (American Chiropractor's Association, 2014). 
Death is considered a natural part of life and a new beginning, not an ending. Elderly live at home and are never placed in long term care facilities, so the gradual loss of health prepares the family members for the death of their loved one. Death comes gracefully, and the final benediction leads the entry into a good life of eternal bliss for the deceased individual. Funeral practices vary among the Amish communities; however, all Amish funeral preparations reflect Amish core values. Family and friends in the local church districts take over the farm and household chores for the bereaved family. Wellestablished funeral rituals are in place to help unburden the family from worrisome choices. Three couples are appointed to extend invitations and oversee funeral arrangements including food preparation, seating arrangements, and coordination of parking for a large number of horses and carriages. In many Amish communities, a nonAmish undertaker takes the body to a funeral home for embalming. The body is returned to the family home in a simple hardwood coffin within a day (Amish Studies, 2014).

This research attempts to provide a better understanding into the health practices of the Amish groups residing in Ashtabula Ohio. The focus of the study was on the immunization practices of the Amish groups and their belief, attitudes, opinions and experiences that influence their decisions regarding immunizations, whether they deferred childhood immunizations, or did not defer. Additionally, this study investigated if the differences depend on age, gender, and Amish order. The study provides insight into educational needs this group may have relating to vaccines and vaccine preventable diseases. 


\section{Problem Statement}

Amish communities have persistently low childhood immunization rates. The reason for the low rate has not been clearly identified. Previous research has speculated that access to health care, religious factors, and fear might be reasons that Amish parents refuse childhood immunizations.

The World Health Organization (WHO) supports the fact immunizations are among public health's greatest triumphs. Despite this fact low immunization rates continue to be an acknowledged public health problem. The United States has certain policy interventions that have contributed to a higher rate of immunization coverage, such as the immunization requirements for pre-school and school entry. Currently, all fifty states have vaccination requirements for school entry; however, all fifty states permit exemption from vaccination for various reasons. All fifty states permit vaccination exemptions for medical reasons; and forty eight states permit exemptions for religious reasons. Additionally, there are nineteen states that permit exemptions for philosophical reasons. Ohio is one of the states that permit exemptions for all of these reasons (Omer, Salmon, Orenstein, DeHart, \& Halsey, 2009).

Significant health benefits have resulted due to the successful immunization of children and adults in the United States. A reduction in morbidity and mortality, costsavings to the health system, and overall benefits to society have resulted from providing immunizations. Although progress has been made in increasing the number of individuals who are protected through immunization there remain certain groups in the United States 
that remain under-immunized (Diekema, 2012). The Amish population is one of the under-immunized groups.

Immunization policies and requirements vary among states; these variations are associated with state-level exemption rates. States with lenient immunization policies demonstrate increased rates of vaccine preventable diseases. Refusal of immunization increases the risk of disease not only for the individual but also for the entire community. Issues remain regarding the constitutional rights of unvaccinated children and the rights of individuals in communities. Vaccine coverage levels remain low in many Amish communities. Amish communities do not accept immunizations as widely as non-Amish communities. Health care practices vary considerably among Amish communities; although they all believe God is the ultimate healer. The Amish religious doctrine does not specifically prohibit immunizations; however, different Amish orders interpret information in their individual Ordnung differently. In general, Amish individuals are less likely to seek medical preventive measures. Some Amish parents have their children receive some immunizations and others do not take any immunizations. There are some Amish who take most immunizations for their children; however, they do not have their children receive their immunizations on the recommended schedule (ACHD, 2013). This study sought to better understand the reasons the Amish in Ashtabula Ohio have low Immunization rates.

\section{Purpose of the Study}

The purpose of the study was to determine the knowledge, beliefs, opinions, and attitudes that influence an Amish parent's decision to refuse some or all immunizations 
for their children. Additionally, determining whether or not the difference depends on age, gender, or Amish order, was investigated. The reason Amish parents choose to follow an alternative immunization schedule for their children, was also investigated. The literature provides an understanding of the reasons Amish parents in some other communities provided for noncompliance with the recommended immunization schedule. The method for investigation and specific survey questions are provided in Chapter 3 and in Appendix A.

\section{Research Questions and Hypotheses}

Four research questions and hypotheses were used as structure for this study in an attempt to determine the difference in Amish parent's knowledge, beliefs, attitudes, and opinions toward child hood immunizations, between those who immunize their children according to the recommended schedule and those who do not. Additionally, whether the potential difference depended on age, gender, and Amish order was also determined. The four research questions understudy included:

Research Question 1: What is the difference in Amish parent's knowledge, belief, attitudes, and opinions, toward childhood immunizations between those who immunize their children according to the recommended schedule and those who do not?

$H_{0} 1$ : There is no difference in Amish parent's knowledge, belief, attitudes, and opinions toward childhood immunizations between those who immunize their children according to the recommended schedule and those who do not. 
$H_{1} 1$ : There is a difference in Amish parent's knowledge, belief, attitudes, and opinions toward childhood immunizations between those who immunize their children according to the recommended schedule and those who do not.

- Dependent variable: Knowledge of protective factors/safety factors, personal/philosophical beliefs, attitudes and opinions regarding access barriers

- Independent variable: Receive recommended immunizations on schedule (yes, no)

- Statistical analysis: MANOVA

Research Question 2: What is the difference in Amish parent's knowledge, belief, attitudes, and opinions toward childhood immunizations between those who immunize their children according to the recommended schedule and those who do not, and does the difference depend on Age group?

$\mathrm{H}_{2} \mathrm{O}$ : There is no difference in Amish parent's knowledge, belief, attitudes, and opinions toward childhood immunizations between those who immunize their children according to the recommended schedule and those who do not and the difference is not affected by age group.

$H_{2} 1$ : There is a difference in Amish parent's knowledge, belief, attitudes, and opinions toward childhood immunizations between those who immunize their children according to the recommended schedule and those who do not and the difference is affected by age group.

- Dependent variable: Knowledge of protective factors/safety factors, personal/philosophical beliefs, attitudes and opinions regarding access barriers 
- Independent variable (1): Receive recommended immunizations on schedule (yes, no)

- Independent variable (2): Age

- Statistical analysis: MANOVA

Research Question 3: What is the difference in Amish parent's knowledge, belief, attitudes, and opinions toward childhood immunizations between those who immunize their children according to the recommended schedule and those who do not and does the difference depend on gender?

$H_{3} \mathrm{O}$ : There is no difference in Amish parent's knowledge, belief, attitudes, and opinions toward childhood immunizations between those who immunize their children according to the recommended schedule those who do not and the difference is not affected by gender.

$H_{3} 1$ : There is a difference in Amish parent's knowledge, belief, attitudes, and opinions toward childhood immunizations between those who immunize their children according to the recommended schedule and those who do not and the difference is affected by gender.

- Dependent variable: Knowledge of protective factors/safety factors, personal/philosophical beliefs, attitudes and opinions regarding access barriers

- Independent variable (1): Receive recommended immunizations on schedule (yes, no)

- Independent variable (2): Gender

- Statistical analysis: MANOVA 
Research Question 4: What is the difference in Amish parent's knowledge, belief, attitudes, and opinions toward childhood immunizations between those who immunize their children according to the recommended schedule and those who do not and does the difference depend on Amish Order?

$\mathrm{H}_{4} \mathrm{O}$ : There is no difference in Amish parent's knowledge, belief, attitudes, and opinions toward childhood immunizations between those who immunize their children according to the recommended schedule and those who do not and the difference is not affected by Amish Order.

$H_{4} 1$ : There is a difference in Amish parent's knowledge, belief, attitudes, and opinions toward childhood immunizations between those who immunize their children according to the recommended schedule and those who do not and the difference is affected by Amish Order.

- Dependent variable: Knowledge of protective factors/safety factors, personal/philosophical beliefs, attitudes and opinions regarding access barriers

- Independent variable (1): Receive recommended immunizations on schedule (yes, no)

- Independent variable (2): Amish order

- Statistical analysis: MANOVA

\section{Theoretical Framework}

The theoretical framework for this study was the PEN-3 Cultural Model. The PEN - 3 Cultural model puts culture first in public health research and health promotion projects. C. Airhihenbuwa developed this model in 1995. It focuses on the role of 
cultural influences, cultural beliefs, and experiences in health and health behaviors of individuals in a community. The framework utilizes three domains, cultural empowerment, relationships \& expectations, and cultural identity. The cultural empowerment domain categorizes factors into three categories. These categories include perceptions, enablers, and nurtures. Perceptions consist of the knowledge, attitudes, values, and beliefs of the individuals. Enablers consist of the cultural, societal, systematic, and structural forces that affect change and nurturers refer to the degree that attitudes, beliefs, and actions are influenced, mediated, and nurtured by extended family, friends, peers, and the community (Cowdery, Parker, \& Thompson, 2010). The relationships and expectations domain assesses perceptions, enablers, and nurturers of behavior from a cultural point of view. Cultural identity includes the individual, the extended family, and the neighborhood in factors that enhance or hinder preventative health decisions and actions (Airhihenbuwa, 1995).

\section{Nature of the study}

I used a correlational research study to determine if there was a correlation between the knowledge, beliefs, opinions, and attitudes among Amish parents and their decision to immunize their children according to the recommended immunization schedule. Additionally, I determined if the difference depended on age, gender, or Amish order. A questionnaire, named the Amish Immunization Questionnaire, containing 20 questions was the instrument used for this study. Wenger et al. (2011) and Yoder et al. (2011) identified variables affecting Amish immunizations in other communities, which include issues regarding access to immunizations, religious/cultural beliefs, and fear of 
immunizations. In this study I sought to determine a correlation between knowledge, beliefs, attitudes, and opinions of Amish parents in Ashtabula County and their decision to immunize their children according to the recommended immunization schedule. It also determined if age, gender, or Amish order affects the knowledge, beliefs, attitudes and opinions of Amish parents, and their decision to immunize their children, or to defer immunizations.

\section{Definitions}

Complete Primary Immunization Series for children: Children who are immunized by 24 month of age with 4 DTaP, 3 Polio, 1 MMR, 3 Hib, 3 Hepatitis B, 1 Varicella, and 4 PVC vaccinations.

Minimum intervals: Minimum spacing between doses of vaccines.

Vaccine for Children (VFC) Program: A federal program that provides free immunizations for qualifying children.

Alternative Immunization Schedule for children: An immunization schedule where parents choose to have their children receive some immunizations; however, the children have not received all recommended immunization for their age.

Missed opportunity information: Information obtained about children who started their immunizations late, the drop off rate for certain immunizations, and children who are missing at least one of the recommended immunizations for their age.

\section{Assumptions}

Access to all Amish families was not possible to obtain. There is not an Amish Directory available for the county so information was obtained through Amish 
community bishops and elders, and the main county resident directory. Many, but not all Amish families, are listed in the main directory. Not all Amish parents in the community were willing to complete the questionnaire; however, provided this information, it is assumed those parents who did participate answered the questionnaire honestly, although there is no way to confirm the level of truthfulness of each respondent. The respondent may have not fully understood the question, as individuals may have read differently into each question, and their reply was based on their interpretation.

Additionally, not all Amish parents in the community were willing to complete the questionnaire. Although it is known that a group of Swartzentruber Amish reside in Ashtabula County no information was able to be obtained from this group regarding their reason for not accepting immunizations. Some members from this group did return the questionnaires in the provided envelope. The questionnaires were not completed; however, a note stating that they did not believe in completing surveys or in taking immunizations was included.

This study adds to an existing body of literature reporting reasons for underimmunization among Amish communities. It also provides information on the knowledge, beliefs, opinions and attitudes that influence Amish parent's decisions regarding immunizations. Additional information was examined to determine whether age, gender, or Amish order affects parental decision to comply with the recommended immunization schedule.

The study is significant due to the fact there had never been a study done to determine the reasons Amish parents in Ashtabula County do not take some, or all 
immunizations for their children. Similar studies conducted in other Amish communities demonstrate various reasons reported for not accepting immunizations. It was important to determine the reasons Amish parents refuse immunizations in Ashtabula County so attempts can be made to address the reasons. The results of this study provide information that could be useful in developing educational programs for addressing the lower immunization rates among the Amish population. Public health professionals in Ashtabula County can tailor programs to address the concerns of this population.

\section{Scope and Delimitations}

As the limitations of a study, several delimitations may have affected the outcome. Delimitations of a study are aspects the research can control. The results of this study are limited to Amish parents residing in the geographic area of Ashtabula County Ohio. Results may not be generalized to other Amish populations located in other areas of Ohio or other states. A quantitative research study was the only method applied, however a qualitative portion may have greatly benefitted the outcome of the results.

\section{Limitations}

The study was limited in many ways. Limitations are aspects of the study that the researcher cannot control. Successful contact with all Amish families was not possible to obtain. There is not an Amish Directory available for the county; therefore, information was obtained through the main county directory and Amish community bishops and elders. Many, but not all Amish families are listed in the main directory. Additionally, not all Amish parents in the community were willing to complete the questionnaire. Although it is known that a group of Swartzentruber Amish reside in Ashtabula County no 
information was able to be obtained from this group regarding their reason for not accepting immunizations. Some members from this group did return the questionnaires in the provided envelope. The questionnaires were not completed; however, a note stating that they did not believe in completing surveys or in taking immunizations was included.

\section{Significance}

This study adds to an existing body of literature reporting reasons for underimmunization among Amish communities. It also provides information on the knowledge, beliefs, opinions and attitudes that influence Amish parent's decisions regarding immunizations. Additional information was examined to determine whether age, gender, or Amish order affects parental decision to comply with the recommended immunization schedule.

The study is significant due to the fact there had never been a study done to determine the reasons Amish parents in Ashtabula County do not take some, or all immunizations for their children. Similar studies conducted in other Amish communities demonstrate various reasons reported for not accepting immunizations. It was important to determine the reasons Amish parents refuse immunizations in Ashtabula County so attempts can be made to address the reasons. The results of this study provide information that could be useful in developing educational programs for addressing the lower immunization rates among the Amish population. Public health professionals in Ashtabula County can tailor programs to address the concerns of this population. 


\section{Summary}

The Amish lifestyle is characterized by a strong Christian religion that traces back to their origins in Switzerland. The cornerstone of Amish religion is obedience and yielding to God, the church, and separation from the outside world. They have maintained an ethnic subculture by successfully resisting acculturation and assimilation. They attempt to maintain cultural customs that preserve their Amish identify and resist assimilation into American culture by emphasizing separation from the world.

The Amish Ordnung (German, meaning order) is a set of rules the Amish live by. Practices may vary among church districts. What is acceptable in one Amish community may not be acceptable in another. Groups of Amish may separate over matters, such as the width of a hat-brim or the color of their buggies for example. A bishop serves as the spiritual head of the church within a district. With the help of the ministers, the bishop interprets and monitors the church doctrine for a specific district and solves disputes. Although Amish religious doctrine does not specifically prohibit immunizations, information in specific Ordnungs can be interpreted to support the non-acceptance of all or some immunizations.

In general, immunization rate coverage among Amish communities is low. Outbreaks of vaccine preventable diseases among Amish populations have been attributed to a low rate of immunization coverage in these communities. Researchers have identified a variety of potential reasons the Amish population refuse some or all immunizations for their children. Formal studies had not been conducted to determine the reason for the low immunization coverage rate among the Amish population in Ashtabula 
County, Ohio. This study sought to uncover the reasons Amish parents in Ashtabula County refuse some or all immunizations for their children. It was also determined whether or not the difference depends on age, gender, and Amish order. This chapter is followed by a review of the pertinent literature in Chapter 2. Chapter 3 follows with a description of the study design, including participants, procedures, assessments to be used, and how information gathered was assessed. Chapter 4 provides information on data analysis and Chapter 5 provides conclusions and recommendations based of the results of this study. 
Chapter 2: Literature Review

\section{Introduction}

The vaccine era started in 1796 when Edward Jenner demonstrated inoculation with cowpox would protect against smallpox; although it was approximately 100 years until the next vaccine was introduced to protect against rabies. In the $18^{\text {th }}$ and $19^{\text {th }}$ centuries, approximately one out of every ten individuals died from smallpox. At the turn of the twentieth century, smallpox was still a dangerous disease worldwide. The smallpox vaccine was in short, supply initially and it was difficult to store. It had to be stored in cool conditions and would not survive in hot climates. A hardier dried smallpox vaccine was developed in the 1920s; however, the quality was inconsistent (WHO, 2014).

A major outbreak of smallpox occurred in New York City in 1947. As a result the World Health Organization took over the health function of the League of Nations. The Smallpox Eradication Program was started in several countries, including the U.S. with the goal of eradicating smallpox. The last naturally occurring case of smallpox in the world was in 1977. In 1979 a global commission declared smallpox was eradicated.

During the twentieth century many new vaccines were developed for use to protect against a variety of diseases. Significant benefits to health have resulted due to the successful practice of immunizing children and adults in the United States. There has been a dramatic reduction in morbidity and mortality, cost-savings to the overall health care system, which benefits the entire society. With the exception of water sanitation, nothing has had a greater effect on the reduction on morbidity and mortality than immunizations (Zhou et al., 2014). 
It is estimated immunizations provided to infants and young children over the past two decades will prevent approximately 322 million illnesses, 21 million hospitalizations, and 732,000 deaths. Additionally, immunizations will save approximately 295 billion dollars in direct medical costs (CDC, 2014).

A resurgence of several vaccine preventable diseases has emerged. Fading memories of the once devastating vaccine preventable diseases and concerns over vaccine safety have contributed to an increase in this resurgence of nearly forgotten diseases such as measles. Measles was officially declared eradicated in the United States in the year 2000; however, 592 individuals residing in the U.S. developed measles in 2014 (CDC, 2014).

The rates of diseases such as pertussis, measles, mumps, and other common childhood illness have been greatly reduced and some diseases have been eliminated. Prior to the availability of the pertussis vaccine, which became available in the 1940s more than 200,000 cases of pertussis were reported each year and more than 500,000 cases of measles were reported each year prior to 1963 when the vaccine became available (AAP, 2013). In 2005 only 3,182 cases of pertussis and 44 cases of measles were reported in the United States demonstrating the success of immunizations (AAP, 2013).

Despite demonstrated success tens of thousands of children and adults continue to develop vaccine preventable diseases and the number of some vaccine preventable diseases has increased over the past decade. In 2011, the number of measles cases in the United States increased to more than 120 cases that was the highest number of cases 
reported since 1996. Reported measles cases for 2014 increased significantly. The number of reported pertussis cases increased to 9,143 cases in 2010 . Unfortunately, this number included ten infant deaths (MMWR, 2011). In January 2011, Ashtabula County had an outbreak of pertussis in the Amish community that resulted in the death of a six week old Amish child. Increasing childhood immunization rates was one of the earliest priorities of the Clinton Administration. This initiative was developed as a result of information demonstrating a disturbing gap in the immunization rate for children residing in the United States. The goals of this initiative were to increase the immunization coverage rates to $90 \%$ or higher for children two years of age. Significant progress was achieved toward this goal; however, there remain certain groups in the United States that are under-immunized. The Amish community is one group that remains underimmunized (Diekema, 2012).

An indicator of the Healthy People 2010 project was to increase the immunization rate for children in the United State to $90 \%$ or greater. Since the Healthy People 2010 goal was not achieved for this indicator, the same indicator has been included in the Healthy People 2020 goals. The National Immunization Survey (NIS) monitors the coverage of immunizations among children 19 through 35 months. Information provided by NIS demonstrates the national rate for all immunizations is approximately $77 \%$. Information further shows that coverage level with the longer standing vaccines is higher than the coverage rate with the newly recommended vaccines. Coverage rates vary by state and disparities in coverage still exist (CDC, 2011). 


\section{Literature Search Strategy}

Literature review was conducted using several sources of information.

Databases searched included CINAHL, Medline, and PubMed. Information was accessed using the general search terms "Amish" and "immunizations" as the root of all inquiries. In addition to these words, other search words such as "children", "communicable disease outbreaks", "Amish culture", "immunization refusals", and "vaccine preventable diseases" were used to narrow the search. From articles found through these search strategies a review of references utilized by previous authors was conducted to locate additional sources of information.

\section{Theoretical Foundation}

The PEN-3 model is partially derived from the health belief model, the theory of reasoned action, and the PRECEDE-PROCEED model. The PEN acronym includes perceptions, enablers, and nurturers. Perceptions pertain to knowledge, beliefs, attitudes, and values that may facilitate or hinder motivation for behavior. Enablers include societal or systemic forces that may augment or hinder health behaviors. Nurturers are reinforcing factors that an individual may receive from significant others, such as family, peers, or religious leaders (Airhihenbuwa, 1995).

\section{Literature Review}

The effects of immunizations have shown significant health benefits in the United States and in other countries. Despite this benefit, immunization rates remain an acknowledged public health concern. The following literature review provides insight into concerns with under-immunized communities and specific information regarding 
reasons Amish individuals provide for non-compliance for their children. Diekema (2012) found lack of accurate knowledge of immunizations to be a barrier. Only $50.4 \%$ of parents surveyed had accurate knowledge of immunizations. Immunization hesitancy has complex social and cultural origins and recently more parents are refusing certain immunizations (Opel, Diekema, Lee, \& Marcuse, 2009).

The largest numbers of unvaccinated children live in states that permit philosophical exemptions to laws requiring immunization for children when they enter school. These states include (a) California, (b) Illinois, (c) New York, (d) Washington, (e) Pennsylvania, (f) Texas, (g) Oklahoma, (h) Colorado, (i) Utah, and (j) Michigan. Of these ten states, seven have Amish communities. These include (a) Colorado, (b) Illinois, (c) Michigan, (d) New York, (e) Oklahoma, (f) Pennsylvania, and (g) Texas (Smith, Chu, \& Barker, 2004).

Outbreaks have occurred among underimmunized Amish communities in the United Stated. In 2009 and 2010 forty seven cases of pertussis were identified in an outbreak in an Amish community in Illinois. Two infants from the community were hospitalized with pertussis. The local health department staff worked with the Amish community on a campaign to provide immunizations in attempt to control the outbreak. Results of the campaign indicated the Amish in this particular community did not universally reject vaccines, and their practices regarding immunization were open to change in an outbreak situation. A targeted successful immunization campaign was conducted with 254 Amish individuals receiving pertussis-containing vaccine (Marino et al., 2013). 
An earlier study reported a pertussis outbreak that occurred in an Amish

Community in Kent County, Delaware in 2005. This outbreak involved 345 cases, mainly in preschool-aged children. The local health department obtained data through household interviews; 96 households were interviewed. The results of the interviews demonstrated $45 \%$ of parents reported not immunizing any of their children, $42 \%$ reported immunizing some of their children, and $13 \%$ did not provide an answer to this question. Parents not immunizing their children stated the fear of side effect as the main reason, while 19 parents providing this as a reason, 13 parents reported they did not think about it as being important, and 11 did not provide a reason for non-compliance with vaccination recommendation (CDC, 2006).

A small outbreak consisting of five cases of polio in an Amish community in central Minnesota caused concern for public health officials. Polio was declared to be eradicated in the United States in 1979. There had been no reported cases in the United States for several years prior to this occurrence (Alexander et al., 2009).

Polio can cause serious illness. The disease was once very common in the United States. It killed and paralyzed thousands of individuals before a vaccine was developed. An epidemic in 1916 killed approximately 6,000 people and paralyzed more than 27,000 more. In the early 1950 s, there continued to be more than 20,000 cases documented in the United States each year.

The National Foundation for Infantile Paralysis was organized to raise funds to assist victims of polio and to fund research. Through the use of research funds, Jonas Salk developed a vaccine to protect against polio in 1955. Public immunization clinics to 
protect against polio began that same year. By the year 1960, the cases of the disease had dropped to approximately 3,000 per year. In 1960, Albert Sabin developed an oral polio vaccine. The oral vaccine contained attenuated or weakened poliovirus. Mass immunization clinics providing both types of vaccine proved to be extremely successful. By the year 1979, there were only approximately 10 cases reported annually in the United States. Due to the success of the polio immunization program in the United States and other countries, a worldwide effort to eliminate polio was begun (CDC, 2014).

With the declaration polio had been eradicated in the United States, the CDC became immediately involved in investigating the cases among the Amish community in Minnesota. Once the CDC confirmed the diagnosis health officials immediately were concerned as to where the virus originated and where it might have spread. The disease was first found in an 8-month old unvaccinated Amish girl. The Minnesota Department of Health and the CDC conducted an investigation. As a result of the investigation, the researchers reported the first known occurrence of community circulation of a vaccinederived poliovirus in an under-immunized Amish community (Alexander et al., 2009).

The investigation was not able to determine the original source of this outbreak; however, it is believed the source was an immune-deficient individual who was exposed to oral polio vaccine outside the United States. Oral polio vaccine has not been used in the United States since the year 2000 due to the fact it actually caused vaccine-associated paralytic polio in some cases. Although inactivated polio vaccine has not been used to immunize individuals in the United States since the year 2000, oral polio vaccine 
continues to be used in countries where wild polio infections continue to occur (Alexander et al., 2009).

Prior to this small outbreak among the Amish in 2005, there had been no reported cases of polio in the United States since 1979. In 1979 there were a total of 17 confirmed cases of polio reported in the United States and Canada. Fourteen of these cases were unvaccinated Amish individuals. Two cases were in unvaccinated non-Amish individuals who lived in or near an Amish community. One case was seen in an Amish infant who was immunized with oral polio vaccine 5 days prior to becoming ill. The first cases were diagnosed in an Amish female residing in Pennsylvania. It is believed the disease spread from one unvaccinated Amish group to another. Transmission occurred due to extensive travel to large social gatherings among the Amish population. Individuals who became ill were from Pennsylvania, Iowa, Wisconsin, and one from Ontario Canada (CDC, 1979).

The unvaccinated Canadian Amish woman who developed polio had attended an Amish wedding in the United States. Fifteen of these cases resulted in paralytic disease. The CDC notified all 21 states where Amish reside of these cases and recommended immunization for the Amish communities. These states included Delaware, Florida, Georgia, Illinois, Indiana, Iowa, Kansas, Kentucky, Maryland, Michigan, Minnesota, Missouri, New Jersey, New York, Ohio, Oklahoma, Pennsylvania, Tennessee, Virginia, and Wisconsin (CDC, 1979).

In a study to examine the immunization rates in the state of New York, it was determined religious exemptions to immunization in the state nearly doubled over the past decade. One possible reason for the increase in religious exemptions was due to the 
fact the state has seen a significant growth in the Amish population. The Amish population increased by $22 \%$ between the years 2010 and 2012. Not all Amish parents refuse immunizations for their children; however, overall Amish children are underAttitudes of the Amish toward preventive health care partly contribute to their decision not to utilize preventive practices such as immunizations. The church does not specifically prohibit immunizations; however, they are not encouraged. Amish cultural practices seek to avoid dependence on government assistance; therefore, many consider accepting free immunizations a form of assistance from the government. Due to low immunization rates among this community herd, immunity is often not acquired. Outbreaks of measles, rubella, Haemophilus influenza and polio have disproportionately affected Amish communities (Yoder \& Dworkin, 2006).

Amish rely on folk remedies and other types of alternative care. Amish individuals with chronic illnesses may seek modern medical care only after symptoms become severe and alternative measures have not been beneficial. Amish families who have sought modern medical care for their children for chronic conditions, such as cystic fibrosis can be open to effective modern therapy and medical interventions including intravenous antibiotic administration, and some immunizations for their children with cystic fibrosis. Parents were willing to permit some immunizations following extensive education regarding the benefits of immunization to protect their children against certain vaccine preventable diseases. Several vaccine preventable diseases can place a child with an underlying chronic condition like cystic fibrosis at increased risk for complications (Henderson \& Anbar, 2009). 
There are a variety of factors that affect the health care of the Amish population. The Amish have a strong cultural belief in home remedies and folk medicine. Many Amish distrust modern medicine. The Amish are often subjected to fraud and medical exploitation. Dishonest salesmen from outside the Amish community target the Amish communities with quack cures often by quoting scriptures. Amish cultural beliefs make these natural alternative treatments sound acceptable. Chelation therapy, radon mines, Tijuana clinics, and herbal supplements are types of health fraud that have been promoted to the Amish. Many of these dishonest salesmen discredit the modern medical professionals claiming there is a massive conspiracy by licensed health care practitioners, drug manufacturing companies, and medical associations (Weyer, et al, 2003).

Transportation is a barrier to health care for the Amish. Arranging transportation can often be time consuming and expensive. When health services are sought due to an illness the Amish prefer to receive services at a single location. This is not usually the case. They are often seen by a healthcare provider then sent someplace else to have lab work drawn or to a pharmacy to pick up a prescription. Additionally Amish individuals believe that doctors and hospitals prescribe too much care including follow up visits once the individual is well. This involves more cost related to travel and medical bills. This also contributes to the lingering concern of distrust in healthcare providers among the Amish.

Between December 1999 and February 2000 an outbreak of Hib disease occurred in a group of Amish in Pennsylvania. None of the children who contracted Hib disease had been immunized. Parents from the Amish group were surveyed about their attitudes 
toward childhood immunization and other preventive health care. Sixty six parents were interviewed. All individuals reported knowing about the recent Hib outbreak in the community. Seventy-seven percent of parents reported they had not had all of their eligible children immunized with $H i b$ vaccine. Reasons provided for failure to immunize their children varied. More than half of the parents reported they did not believe that immunizations were a priority compared with other activities that were required in their daily lifestyle. Eleven percent of parents reported fear of immunization side effects and $22 \%$ reported philosophical reasons for not immunizing their children. Only $6 \%$ reported religious objections as the reason for not immunizing their children (Fry et al., 2001) Between April 1990 and April 1991 the ODH received 278 reports of rubella cases. All except two cases were among members of the Amish communities in northeast Ohio. In August 1990 the ODH began investigating the increasing number of rubella cases in these communities. This outbreak included eight counties in Ohio where large settlements of Old Order Amish reside. The majority of cases were found in Medina, Wayne, and Holmes counties. The disease was thought to have spread through infected individuals who attended barn raisings, church gatherings, weddings, and funerals throughout the Amish communities in the eight counties. Amish individuals from other states, including Minnesota, Tennessee, Iowa, and New York attended gathering in these Amish communities during this time frame. A total of 85 probable cases were reported to the Ohio immunization representative by program directors in these other states (Jackson, Payton, Horst, Halpin, \& Mortensen, 1993). 
The Old Order Amish believe in separating themselves from the world and modern conveniences. Worldliness is to be avoided. Most of the individuals interviewed denied receiving immunization to protect against rubella. Avoiding worldliness in this group of Amish is most often interpreted to include immunizations and blood transfusions because this would interfere in outcomes they believe to be demonstration of Divine Providence (Jackson et al., 1993).

Holmes County, Ohio is one of the largest Amish communities in the world. A survey was conducted among Amish parents in Holmes County in attempt to gain understanding of their views on immunizations. Results demonstrated that more Amish parents reported accepting immunizations than the authors expected; however, most of the parents reported they only permitted certain immunizations for their children. The study also demonstrated that decisions regarding immunizations were not strictly influenced by religious beliefs, and many parents reported decisions to exempt certain immunizations on the basis of ethical values. Additionally parents reported concern over adverse effects of immunizations as a major barrier. The Amish value separation from the secular world and are less likely to seek medical care from modern medical practitioners; therefore they lack the education provided by health professionals regarding immunizations. They are more likely to rely on peer educators within their community for information on immunizations and immunization safety issues (Wenger, McManus, Bower, \& Langkamp, 2011). Immunizations can cause adverse effects; however, immunizations are held to the highest standard of safety. Currently the United States has the safest and most effective 
vaccine supply in history. Before vaccines are licensed years of testing are required by law and once vaccines are licensed monitoring for safety and efficacy is continued. The CDC and the Food and Drug Administration (FDA) continually monitor and work to make vaccines safe. It is extremely rare that a child is injured by an immunization. In the event a child is injured the family can apply for compensation through the National Vaccine Injury Compensation Program ([VICP] CDC, 2014).

\section{Summary and Conclusions}

Chapter 2 provided information on the history and development of immunizations and the success of immunization campaigns. Several articles were reviewed and summarized discussing illness and outbreaks of vaccine preventable disease in Amish communities. Results of previously conducted studies attempting to determine low rates for immunization among the Amish population were also summarized. Information gained from the literature review provided a basis for the study to be conducted. Based on previous studies there may be a variety of reasons that Amish populations have lower rates of immunization coverage. This study attempted to address the issue with the Amish population in Ashtabula County.

The next chapter provides information on how this study was performed, how the participants were identified, the questions that were asked, and how the information was organized and analyzed. 
Chapter 3: Research Method

\section{Introduction}

Chapters 1 and 2 provided detailed information about immunizations, the recommended immunization schedule for children in the United States, and underimmunized communities. The two chapters also discussed Amish culture and the lower rates of immunizations among Amish populations in the United States. Reasons Amish populations experience lower rates of immunization coverage were discussed in the literature review. The reasons differ among Amish orders and geographic area.

Unknown; however, was how the Amish populations in Ashtabula County view immunizations, and how their knowledge, attitudes, beliefs, and opinions affect the immunization rates in the county. It was also unknown if the difference in knowledge, belief, attitudes, and opinions, toward childhood immunizations between those who defer childhood immunization and those who do not defer childhood immunizations, depends on age, gender, and Amish order.

The purpose of this chapter is to describe the quantitative method used in determining an understanding of the knowledge, attitudes, beliefs and opinions among the Amish population in Ashtabula County relating to immunizations, and the role these have in their decision to immunize according to the CDC recommendations, and whether or not the differences depend on age, gender, and Amish order. The population, participants, procedures and ethical issues are addressed in this chapter. Chapter 3 discusses the instrument chosen and the measures used, as well as defines the scope and limitation of the design used for this research study. 


\section{Research Design and Rationale}

I used a correlational study to examine the knowledge, beliefs, attitudes, opinions and experiences of Amish individuals who have their children receive all recommended immunizations and those who do not have their children receive all recommended immunizations, and whether the difference depends on age, gender, and Amish order. Correlational studies can be useful for making a prediction to support a theory or test a hypothesis; however, correlation can’t prove a causal relationship (Creswell, 1998).

Qualitative methods of inquiry were considered; however, it would not have been possible to capture as large of a population and the study may have provided too narrow of a scope for the purpose of obtaining countywide data from the Amish population.

Information has been obtained regarding the number of Amish orders and Ordnungs in the county it may now be feasible to conduct a qualitative study with smaller focus groups of individuals belonging to specific orders, to add an additional component to the quantitative portion of the study. The population in the study conducted was large enough to permit obtaining information on Amish cultural groups and their varying beliefs.

\section{Methodology}

A quantitative research design was used to study the topic explored. Creswell (1998) contended quantitative studies are appropriate for examining the relationship among variables. The results can be measured using an instrument so numbered data can be analyzed with the use of statistical procedures. Quantitative data can limit the influence of confounding variables and increase the ability to generalize the study results 
(Creswell, 1998). The theoretical model in Figure 1 displays an organized view of the dependent variables, and independent variables understudy.

Four research questions and hypotheses were used as structure for this study in an attempt to determine the difference in Amish parent's knowledge, beliefs, attitudes, and opinions toward child hood immunizations, between those who immunize their children according to the recommended schedule and those who do not. Additionally, whether the potential difference depended on age, gender, and Amish order was also determined. The four research questions understudy included:

Research Question 1: What is the difference in Amish parent's knowledge, belief, attitudes, and opinions, toward childhood immunizations between those who immunize their children according to the recommended schedule and those who do not?

$H_{0} 1$ : There is no difference in Amish parent's knowledge, belief, attitudes, and opinions toward childhood immunizations between those who immunize their children according to the recommended schedule and those who do not.

$H_{1} 1$ : There is a difference in Amish parent's knowledge, belief, attitudes, and opinions toward childhood immunizations between those who immunize their children according to the recommended schedule and those who do not.

- Dependent variable: Knowledge of protective factors/safety factors, personal/philosophical beliefs, attitudes and opinions regarding access barriers

- Independent variable: Receive recommended immunizations on schedule (yes, no)

- Statistical analysis: MANOVA 
Research Question 2: What is the difference in Amish parent's knowledge, belief, attitudes, and opinions toward childhood immunizations between those who immunize their children according to the recommended schedule and those who do not, and does the difference depend on Age group?

$\mathrm{H}_{2} \mathrm{O}$ : There is no difference in Amish parent's knowledge, belief, attitudes, and opinions toward childhood immunizations between those who immunize their children according to the recommended schedule and those who do not and the difference is not affected by age group.

$H_{2} 1$ : There is a difference in Amish parent's knowledge, belief, attitudes, and opinions toward childhood immunizations between those who immunize their children according to the recommended schedule and those who do not and the difference is affected by age group.

- Dependent variable: Knowledge of protective factors/safety factors, personal/philosophical beliefs, attitudes and opinions regarding access barriers

- Independent variable (1): Receive recommended immunizations on schedule (yes, no)

- Independent variable (2): Age

- Statistical analysis: MANOVA

Research Question 3: What is the difference in Amish parent's knowledge, belief, attitudes, and opinions toward childhood immunizations between those who immunize their children according to the recommended schedule and those who do not and does the difference depend on gender? 
$\mathrm{H}_{3} \mathrm{O}$ : There is no difference in Amish parent's knowledge, belief, attitudes, and opinions toward childhood immunizations between those who immunize their children according to the recommended schedule those who do not and the difference is not affected by gender.

$H_{3} 1$ : There is a difference in Amish parent's knowledge, belief, attitudes, and opinions toward childhood immunizations between those who immunize their children according to the recommended schedule and those who do not and the difference is affected by gender.

- Dependent variable: Knowledge of protective factors/safety factors, personal/philosophical beliefs, attitudes and opinions regarding access barriers

- Independent variable (1): Receive recommended immunizations on schedule (yes, no)

- Independent variable (2): Gender

- Statistical analysis: MANOVA

Research Question 4: What is the difference in Amish parent's knowledge, belief, attitudes, and opinions toward childhood immunizations between those who immunize their children according to the recommended schedule and those who do not and does the difference depend on Amish Order?

$\mathrm{H}_{4} \mathrm{O}$ : There is no difference in Amish parent's knowledge, belief, attitudes, and opinions toward childhood immunizations between those who immunize their children according to the recommended schedule and those who do not and the difference is not affected by Amish Order. 
$H_{4} 1$ : There is a difference in Amish parent's knowledge, belief, attitudes, and opinions toward childhood immunizations between those who immunize their children according to the recommended schedule and those who do not and the difference is affected by Amish Order.

- Dependent variable: Knowledge of protective factors/safety factors, personal/philosophical beliefs, attitudes and opinions regarding access barriers

- Independent variable (1): Receive recommended immunizations on schedule (yes, no)

- Independent variable (2): Amish order

- Statistical analysis: MANOVA

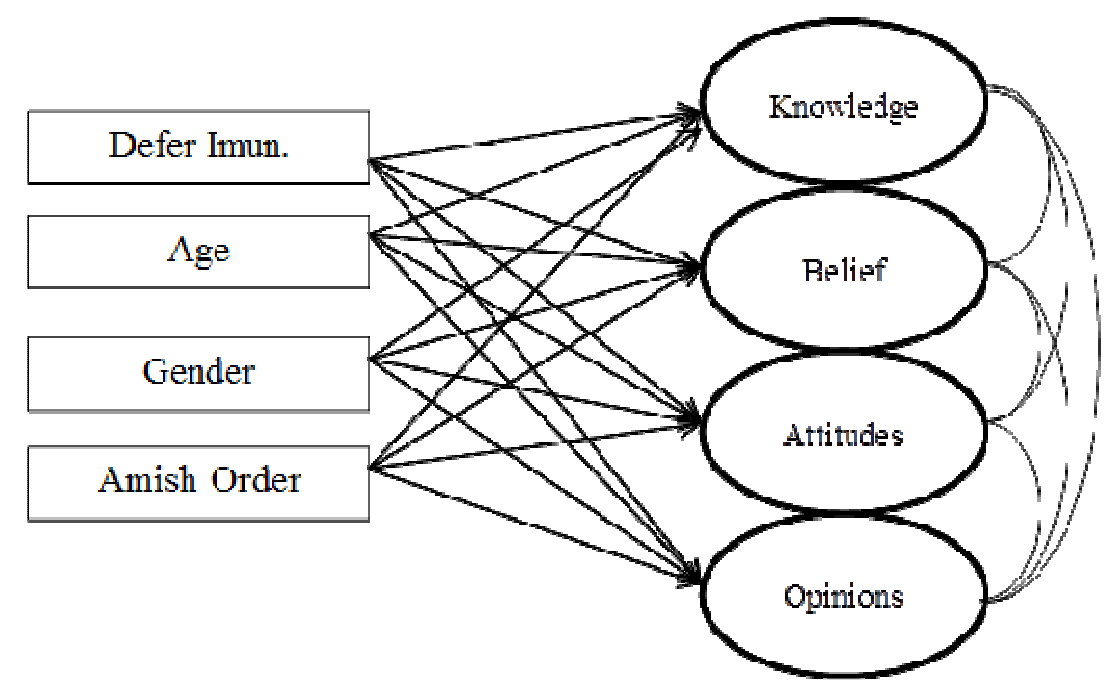

Figure 1. Theoretical model of the variables under study. 


\section{Population}

Participants consisted of eighty-four Amish individuals selected from a convenience sample of Amish individuals who reside in Ashtabula County. The participants included every Amish resident who returned a survey. Every Amish resident listed in the county directory was mailed a survey. This included Amish individuals who take some or most immunizations and those who do not take any immunizations. The families had at least one child; although, the child may have been passed the age when immunizations are recommended at the time this study was conducted. Participants were Amish mothers or fathers of children who reside in Ashtabula County.

\section{Sampling and Sampling Procedures}

Four hundred and two participants were invited to participate in the study by a mailed invitation. Addresses were obtained from the Ashtabula County Directory and from the Bishops in the Amish communities. A questionnaire was sent to all Amish families listed in the directory and to every Amish resident not listed in the directory when the address was obtained from the bishop. I introduced the questionnaire to the participants through a letter explaining the purpose of the study, and informing them of the nature of the intended study. The letter explained to the participant that participation in filling out the questionnaire was voluntary. They were advised they could refuse to answer any question or questions on the questionnaire or choose not to complete the questionnaire. Participants were provided with a phone number to call if they had questions, or wanted to discuss any aspect of the questionnaire with the researcher (Appendix C). The questionnaire was mailed out during the week of August 18, 2015. 


\section{Procedures for Recruitment, Participation, and Data Collection}

Data were collected through a questionnaire. Each potential participant was mailed a copy of the letter describing the proposed study. The questionnaire and a return stamped envelope were also included in the packet that was mailed to potential participants. I mailed 402 questionnaires to potential participants. The questionnaire focused on obtaining nominal information as to the age, gender, and order the participant belonged to through the use of three demographic questions. These variables were analyzed with the use of descriptive statistics. Additional questions analyzed with descriptive statistics included questions regarding parent's knowledge of where immunizations are provided at no cost, where the individuals receive information about immunizations and factors that might influence parents to change their minds. The individual's knowledge, beliefs, attitudes, and opinions regarding immunizations and the recommended immunization schedule were assessed through eight questions on a 6-point Likert-type scale ranging from $1=$ strongly disagree to $6=$ strongly agree. These answers to the questionnaire were used to assess the dependent variables. The yes/no questions are dichotomous variables and were analyzed as nominal data. A Likert-type scale data can be analyzed as interval-level data. Data were organized by creating a spreadsheet from the questionnaires. Each questionnaire was assigned an identification number. Once the information was in the spreadsheet it was entered into SPSS software for data analysis. 
Instrumentation and Operationalization of Constructs

Data were collected through the use of an Amish Immunization Questionnaire. A Mennonite physician, Olivia Wenger M.D, originally created the instrument. Dr. Wenger developed the questionnaire in attempt to understand more about Amish views of childhood immunizations. Dr. Wenger utilized the questionnaire among the Amish population in Holmes County in Ohio (Wenger et al., 2011)

A request for permission to utilize the questionnaire and make some slight modifications was sent to Dr. Wenger. Information for contacting the author was obtained from the journal article. Dr. Wenger provided permission to use the questionnaire with some modifications. Modifications were made so that all questions were worded so quantitative analysis could be completed. There were no open-ended questions on the survey used among the Amish population in Ashtabula County (Appendix C).

\section{Validating the instrument}

Validity of an instrument is determined by whether the instrument measures what it is intended to measure. An instrument that has validity has an inherent degree of reliability (Creswell, 1998). To be effective, a survey instrument should be assessed for validity and reliability. The original instrument was developed previously, and utilized by a researcher who surveyed a group of Amish in Holmes County. Permission was obtained from the author to utilize the instrument; as well as make some slight modifications so the questions could all be analyzed using a quantitative method. A pilot study was conducted with a small group of 30 Amish parents in Ashtabula County to assure 
understanding of the questions, and that they still measured what was anticipated, after they had been modified. Fifty questionnaires were mailed out during the week of July 28 , 2015. Every $5^{\text {th }}$ Amish family listed in the county directory was mailed a survey until a total of 50 families were included. Thirty surveys were returned by August 8, 2015. Based on results of the pilot study reliability could not be obtained for questions 14,18 , and 19. This was due to the fact that not enough participants answered these questions. Information in these questions pertained to individuals who refuse all immunizations or had been advised against accepting immunizations. Individuals who returned the pilot study questionnaires all reported accepting at least some immunizations. It was decided to leave these questions on the survey in attempt to obtain some additional information; however, these questions were not part of the statistical analysis.

\section{Power Analysis (MANOVA)}

A formal power analysis was conducted to determine minimum sample size. Prior to conducting the power analysis, three factors were considered. These three factors were intended power of the study, (b) effect size of the phenomena under study, and (c) level of significance to be used in rejecting the null hypotheses (alpha). Study power is the probability of rejecting a false null hypothesis. As a matter of convention, adequate power to reject a false null hypothesis is .80 (Keuhl, 200). Effect size, is an estimated measurement of the strength of the relationship between variables in the study (Cohen, 1988). The effect size was characterized by Cohen (1988) as Cohen's $f^{2}$ small, medium, and large where each level is associated with a specified effect size. Thus, a small effect $=.10$, medium $=.25$ and large $=.40$. Alpha is defined as how 
confident one is when rejecting the null hypothesis. Social science research convention suggests alpha should be set at .05 . Therefore, with power set at .80 , effect size set at .25 and alpha set at .05 , the sample size required is 82 participants when the sample is split between levels of the independent variable at 41 per group (Faul, Lang, \& Buchner, 2007). Figure 2 displays the power graph for the MANOVA test. As depicted, as power increases, sample size increases.

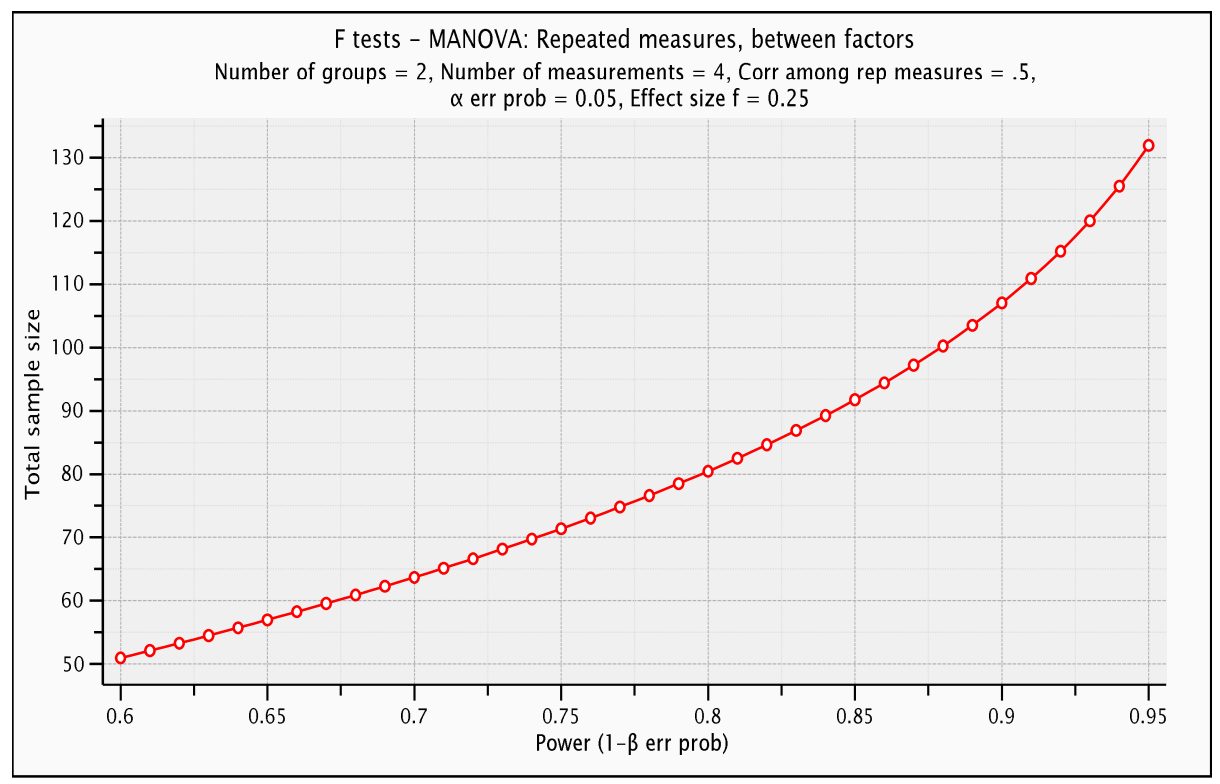

Figure 2. Power analysis graph depicting the relationship between power and sample size for a MANOVA type test.

\section{Operationalization}

Age. Age is an independent variable, and is defined as the length of time an individual has lived or existed (Volden, Langemo, Adamson, \& Oechsle, 1990). Age was determined by the answer provided to Question 2 on the Amish Immunization 
questionnaire. Age is measured at the nominal level. Participants indicated their age in years (Appendix A).

Gender. Gender is an independent variable, and is defined as self-identifying as being male or female (Volden et al., 1990). Gender was determined by the answer provided to question 1 on the Amish Immunization questionnaire. Gender was measured at the nominal level. Participants indicated their gender by answering male or female (Appendix A).

Amish Order. Amish order is an independent variable, and is defined as the affiliation or congregation the individual belongs to which share similar distinctive lifestyles (Amish Studies, 2014). Amish order was determined by the answer provided to question 3 on the Amish Immunization questionnaire. Amish order was measured at the nominal level. Participants indicated their Amish order by answering Old Order Amish, New Order Amish, Swartentruber Amish, or Other (Appendix A).

Knowledge. Knowledge is a dependent variable, and is defined as being familiar with or aware of, and understands (Chinn, 2008) the information or facts regarding protective qualities of immunizations and the safety factors of immunizations, including benefit versus risk. This information was obtained from the answers to questions $7,8,11$, and 12 on the Amish Immunization questionnaire. Questions 7, 8, 11 and 12 offer a likert scale option of choices. The scale ratings range from 1-6 with $1=$ strongly disagree, $2=$ disagree, $3=$ slightly disagree, $4=$ slightly agree, 5= agree and 6= strongly agree (Appendix A). 
Belief. Belief is a dependent variable, and is defined as a feeling of being sure something is true, right, or good (Stanhope \& Lancaster, 2012). This information was obtained from the answers to question 10 on the Amish Immunization questionnaire. Question10 has five parts and was measured on a 6-point Likert scale. The scale ratings range from 1-6 with 1 = strongly disagree, 2= disagree, 3= slightly disagree, 4= slightly agree, 5= agree and $6=$ strongly agree. (Appendix A).

Attitude. Attitude is a dependent variable, and is defined as a way of thinking. (Stanhope \& Lancaster, 2012). This information was obtained from the answers to question 5 on the Amish Immunization questionnaire. This question has five parts and was scaled on a 6-point Likert scale. The scale ratings range from 1-6 with $1=$ strongly disagree, $2=$ disagree, $3=$ slightly disagree, $4=$ slightly agree, $5=$ agree and $6=$ strongly agree. (Appendix A).

Opinion. Opinion is a dependent variable, and is defined as a view or judgment about something (Stanhope \& Lancaster, 2012).This information was obtained from question 9 on the Amish Immunization questionnaire. Question 9 has three parts and these are scaled on a 6-point Likert scale. The scale ratings range from 1-6 with $1=$ strongly disagree, $2=$ disagree, $3=$ slightly disagree, $4=$ slightly agree, $5=$ agree and $6=$ strongly agree. (Appendix A). The seven operationalized variables were extracted from primary sources; individuals were directly surveyed by the use of a questionnaire. The questionnaire was based on some demographic questions; yes/no questions and Likerttype scale questions. The scale ratings range from 1-6 with $1=$ strongly disagree, $2=$ disagree, $3=$ slightly disagree, $4=$ slightly agree, $5=$ agree and $6=$ strongly agree. The 
variables, along with the corresponding survey, and survey questions are organized in table1. Yes or no questions were not statistically analyzed and serve as additional information only.

Table 1

Variables and Corresponding Survey Information

\begin{tabular}{|c|c|c|c|c|}
\hline Variable & Variable type & Survey & $\begin{array}{l}\text { Number of } \\
\text { Questions }\end{array}$ & Questions \\
\hline Age & $\begin{array}{l}\text { Independent } \\
\text { variable }\end{array}$ & $\begin{array}{l}\text { Amish Immunization } \\
\text { Questionnaire }\end{array}$ & 1 & 2 \\
\hline Gender & $\begin{array}{l}\text { Independent } \\
\text { variable }\end{array}$ & $\begin{array}{l}\text { Amish Immunization } \\
\text { Questionnaire }\end{array}$ & 1 & 1 \\
\hline Amish Order & $\begin{array}{l}\text { Independent } \\
\text { variable }\end{array}$ & $\begin{array}{l}\text { Amish Immunization } \\
\text { Questionnaire }\end{array}$ & 1 & 3 \\
\hline Knowledge & $\begin{array}{l}\text { Dependent } \\
\text { variable }\end{array}$ & $\begin{array}{l}\text { Amish Immunization } \\
\text { Questionnaire }\end{array}$ & 4 & $7,8,11,12$ \\
\hline Beliefs & $\begin{array}{l}\text { Dependent } \\
\text { variable }\end{array}$ & $\begin{array}{l}\text { Amish Immunization } \\
\text { Questionnaire }\end{array}$ & 5 & $10(a-e)$ \\
\hline Attitudes & $\begin{array}{l}\text { Dependent } \\
\text { variable }\end{array}$ & $\begin{array}{l}\text { Amish Immunization } \\
\text { Questionnaire }\end{array}$ & 5 & $5(a-e)$ \\
\hline Opinions & $\begin{array}{l}\text { Dependent } \\
\text { variable }\end{array}$ & $\begin{array}{l}\text { Amish Immunization } \\
\text { Questionnaire }\end{array}$ & 3 & $9(a-c)$ \\
\hline
\end{tabular}

\section{Data Analysis Plan}

In an effort to test the four hypotheses, MANOVA analyses were conducted. The analysis was accomplished using the Statistical Package for the Social Sciences (SPSS) software program, Student Version 20.0. This data analysis includes descriptive statistics, means, standard deviation, and frequency where applicable. In addition, histograms are offered, as well as z-scores and Normal Q-Q plots to support assumptions of normality if necessary. Further, regression tables and supporting figures are presented as an effect of condition was found. For these analyses, alpha was set at $p=.05$, meaning the confidence level associated with the results met or exceeded 95\%. Multivariate analysis of variance 
(MANOVA) was used to test hypothesis 1 through 5. MANOVA analysis concludes if there is a significant mean difference in the dependent variables as a result of the independent variables. Specifically, this research determined if a difference existed among the dependent variables, knowledge, belief, attitude, and opinion, between levels of the independent variables, including age, gender, and Amish order.

\section{Threats to Validity}

Validity, according to Creswell refers to the degree to which the researchers are able to draw meaning and useful inference from the results obtained using a particular instrument (Creswell, 1998). The instrument was initially validated by the developer. Threats to validity may have still been encountered with the instrument based on the understanding of the questions by the individuals completing the survey in Ashtabula County. Additionally the honestly of the individuals answering the question will affect the validity. Validity could also be threatened by the current experiences in the Amish community at the time the survey was completed. If the Amish community was experiencing an outbreak of a communicable disease at the time individuals were completing the survey, the answers to some of the questions may have been influenced.

\section{Ethical Procedures}

The participants in this study included Amish parent volunteers who were free to choose whether or not to participate. There was no known harm associated with participating in this study. There were no names on the questionnaires, assuring that all participants remain confidential and anonymous. Returned questionnaires are being stored in a locked cabinet in the researcher's office. Only the researcher and those 
selected to assist in validating the results have access to the questionnaires. Voluntary consent was implied if the questionnaire was returned. The study was approved by the The Ashtabula County Board of Health and Walden University approved the study.

\section{Summary}

Chapter 3 describes the research methodology for the quantitative research study. It also discusses the target population, data collection and analysis procedures. Chapter 4 discusses the data analysis and results. 
Chapter 4: Results

\section{Introduction}

The purpose of this chapter is to describe the results of the Amish Immunization Survey used to gain an understanding of knowledge, attitudes, beliefs, and the role these have in their decision to immunize their child according to the CDC recommendation, and whether or not their decision is impacted by age, gender, or Amish order. The data analysis procedure will be explained for each of the research questions.

\section{Data Analysis Procedure}

Inferential statistics were used to draw conclusions from the sample tested. The Statistical Package for the Social Sciences (SPSS) was used to code and tabulate scores collected from the survey and provide summarized values where applicable including the mean, central tendency, variance, and standard deviation. Multivariate analyses of variance (MANOVA) was used to evaluate the four research questions. The research questions were:

Research Question 1 (RQ1): What is the difference in Amish parents knowledge, belief, attitudes, and opinions toward childhood immunizations between those who immunize their children according to the recommended schedule and those who do not?

Research Question 2 (RQ2): What is the difference in Amish parents knowledge, belief, attitudes, and opinions toward childhood immunizations between those who immunize their children according to the recommended schedule and those who do not, and does the difference depend on age group? 
Research Question 3 (RQ3): What is the difference in Amish parents knowledge, belief, attitudes, and opinions toward childhood immunizations between those who immunize their children according to the recommended schedule and those who do not and does the difference depend on gender?

Research Question 4 (RQ4): What is the difference in Amish parents knowledge, belief, attitudes, and opinions toward childhood immunizations between those who immunize their children according to the recommended schedule and those who do not and does the difference depend on Amish Order?

Prior to analyzing the research questions, data cleaning and data screening were undertaken to ensure the variables of interest met appropriate statistical assumptions. Thus, the following analyses were assessed using an analytic strategy in that the variables were first evaluated for missing data, univariate outliers, multivariate outliers, normality, linearity, homogeneity of variance, homogeneity of variance-covariance matrices, and multicollinearity. Finally, MANOVA analyses were run to test the four research questions-see Table 2

Table 2

Variables and Statistical Tests Used to Evaluate Research Questions 1-4

\begin{tabular}{cccc}
\hline $\begin{array}{c}\text { Research } \\
\text { Question }\end{array}$ & Dependent Variable & Independent Variable & Analysis \\
\hline RQ1 & $\begin{array}{c}\text { Childhood Immunization } \\
\text { Subscales }\end{array}$ & Scheduled Immunization & MANOVA
\end{tabular}

\section{Demographics}

Data were collected from a valid sample of 84 Amish residents from Ashtabula County. All 84 Amish participants belonged to the Old Order. The majority of 
participants were female $(90.5 \%, n=76)$ and the remaining participants were male $(9.5 \%, n=8)$. Of the 84 participants, 47 were between 26 and 35 years old $(56.0 \%), 25$ were between 36 and 45 years old (29.8\%), nine were between 18 and 25 years old $(10.7 \%)$, and three were 55 years or older (3.6\%). Additionally, 49 parents' provided their children with all recommended shots on schedule $(58.3 \%), 33$ provided some of the shots on schedule (39.3\%), and two did not provide any shots $(2.4 \%)$. Displayed in Table 3 are frequency and percent statistics of participants' gender age group, and whether parent's provided their children with all recommended shots on schedule.

Table 3

Frequency and Percent Statistics of Participants' Gender, Age Groups, and Whether Parent's Provided Their Children with all Recommended Shots on Schedule

\begin{tabular}{lrr}
\hline \multicolumn{1}{c}{ Demographic } & Frequency $(n)$ & Percent $(\%)$ \\
\hline Gender & & \\
Male & 8 & 9.5 \\
Female & 76 & 90.5 \\
Total & 84 & 100.0 \\
& & \\
Age Group & & \\
18 - 25 years & 9 & 10.7 \\
26 - 35 years & 47 & 56.0 \\
36 - 45 years & 25 & 29.8 \\
55+ years & 3 & 3.6 \\
Total & 84 & 100.0 \\
& & \\
Shots on Schedule & & \\
All & 49 & 58.3 \\
Some & 33 & 39.3 \\
None & 2 & 2.4 \\
Total & 84 & 100.0 \\
\hline Note. Total $N=84$ & &
\end{tabular}




\section{Analysis of Research Questions 1-4}

Research questions 1-4 were evaluated using MANOVA analysis to determine if any significant differences in Amish parent's knowledge, belief, attitudes, and opinions toward childhood immunizations between those who immunize their children according to the recommended schedule and those who do not, and does the difference depend on age groups, gender, and Amish orders. The dependent variables for research questions 14 were parent's knowledge, belief, attitudes, and opinions toward childhood immunizations. Parent's knowledge was measured by survey questions 7, 8, 11, and 12 on the Amish Immunization questionnaire. Question 7: Following immunization recommendations significantly reduces the likelihood of preventable disease outbreaks in my community. Question 8 had three parts (a-c):

- Question 8a: My parents assured that I received all my shots.

- Question 8b: Most other families in my community were diligent having their children immunized.

- Question 8c: Shots would save our community money by preventing serious illnesses if everyone received them.

Question 11 had five parts (a-g) relating to parent's knowledge of immunization safety:

- Question 11a: Shots inject children with dangerous germs like Polio or whooping cough.

- Question 11b: Shots have too many side effects to be worth the risk of getting them.

- Question 11c: I have heard that some shots have dangerous preservative chemicals in them. 
- Question 11d: Shots can cause high fevers more than one week after they are given.

- Question 11e: Shots can cause too much stress on the system if given all at once.

- Question 11f: Shots can cause brain damage.

- Question 11g: Shots can cause seizures more than one week after they are given.

Question 12 had five parts (a-d) relating to parent's knowledge of immunization safety:

- Question 12a. Shots are protective against diseases.

- Question 12b. My doctor/nurse recommends them.

- Question 12c. Shots are safer overall than the diseases children could get without shots.

- Question $12 \mathrm{~d}$. Not having my child immunized could contribute to a vaccine preventable disease in my community.

Parent's attitudes toward immunization were measured by five parts (a-e) on survey question 5.

- Question 5a. The minister/bishop in my community disagrees with giving shots.

- Question 5b. Other families in my community do not give shots.

- Question 5c. If I give shots it means I'm not putting faith in God to take care of my children.

- Question $5 \mathrm{~d}$. I believe that God would not want me to give shots to my child. 
- Question 5g. I feel giving shots disagrees with my faith or spiritual beliefs in some way.

Parents opinions toward childhood immunization was measured by three parts (a-c) on survey question 9.

- Question a. It is too difficult to get to the doctor's office or clinic for shots.

- Question b. We can't afford shots.

- Question c. Shots are too expensive.

Parent's beliefs were measured by question 10 on the survey. Question 10 had 5 parts (ae):

- Question a. There are too many recommended shots.

- Question b. Giving all the recommended shots at once is too aggressive (hard on the baby).

- Question c. I have heard that some shots come from aborted babies.

- Question d. Babies are too young to handle all of the recommended shots.

- Question e. The diseases shots prevent are not a problem in our community.

Response parameters for the dependent variables were measured on a 6-point Likert-type scale where 1 = strongly disagree, 2 = disagree, $3=$ slightly disagree, $4=$ slightly agree, $5=$ agree, and $6=$ strongly agree. Composite scores were calculated for each variable by averaging case scores across the items for each construct.

The independent variables for research questions 1-4 were whether participants immunize their children according to the recommended schedule (all on schedule) and those who do not (some or none on schedule). Additionally, the independent variables for research questions 2-4 were participants' gender (male, female), age group 
(18-25, 26-35, 36-45, 46-55, and 55+ years old), and type of Amish order, respectively. For age groups, due to low sample sizes participants were grouped into two categories Including 18-35 years old $(n=38)$ and $36+$ years old $(n=15)$. However, since all participants were from the Old Order $(N=84)$, no analyses were conducted to evaluate research question 4.

\section{Data Cleaning}

A sample of 84 Amish residents of Ashtabula County was used. The sample included Amish residents who returned a survey that was mailed to all Amish residents listed in the Ashtabula County directory. Before the data were evaluated, the data were screened for missing data, univariate outliers, and multivariate outliers. Missing data were investigated using frequency counts and 31 cases were found to have not responded to most of the survey items and were removed from the analyses of research questions 13. To retain as many participants as possible, those who did not respond to three or less survey items had their missing scores replaced with the survey items' series mean.

The data were screened for univariate outliers by transforming raw scores to zscores and comparing $z$-scores to a critical range between -3.29 and $+3.29, p<.001$ (Tabachnick \& Fidell, 2007). Z-scores that exceed this critical range are more than three standard deviations away from the mean and thus represent outliers. The distributions were evaluated and no cases with univariate outliers were found.

Multivariate outliers were evaluated using Mahalanobis distance. Mahalanobis distances were computed for each variable and these scores were compared to a critical value from the chi square distribution table. Mahalanobis distance for two dependent 
variables indicates a critical value of 13.82. Results indicated that no cases with multivariate outliers were found to exceed the value. Thus, 84 responses from participants were received and 53 were evaluated by the MANOVA model for research questions 1-3 $(N=53)$. Descriptive statistics of participants' knowledge, belief, attitudes, and opinions by whether they provided their children with the recommended shots on schedule is displayed in Table 4.Additionally, descriptive statistics of the dependent variables by gender and age are displayed in Appendix E.

Table 4

Descriptive Statistics of Participants' Knowledge, Belief, Attitudes, and Opinions of Childhood Immunization by Whether they Provided Shots on Schedule

\begin{tabular}{|c|c|c|c|c|c|c|c|}
\hline Variable & $n$ & Min & Max & Mean & Std. Deviation & Skewness & Kurtosis \\
\hline \multicolumn{8}{|c|}{ All Shots on Schedule } \\
\hline Knowledge & 32 & 4.270 & 6.000 & 5.046 & 0.539 & 0.532 & -0.901 \\
\hline Belief & 32 & 2.600 & 6.000 & 4.163 & 0.898 & 0.442 & -0.301 \\
\hline Attitude & 32 & 1.000 & 3.400 & 2.338 & 0.627 & -0.294 & -0.529 \\
\hline Opinion & 32 & 4.000 & 6.000 & 4.875 & 0.499 & 0.327 & 0.539 \\
\hline \multicolumn{8}{|c|}{ Some/No Shots on Schedule } \\
\hline Knowledge & 21 & 3.400 & 5.530 & 4.479 & 0.552 & -0.505 & 0.228 \\
\hline Belief & 21 & 1.600 & 4.800 & 3.571 & 0.844 & -0.714 & 0.313 \\
\hline Attitude & 21 & 1.000 & 4.400 & 2.400 & 0.681 & 0.932 & 3.179 \\
\hline Opinion & 21 & 2.000 & 5.330 & 4.349 & 1.152 & -1.425 & 0.367 \\
\hline
\end{tabular}

\section{Reliability Analysis}

Reliability analyses were run to determine if the dependent variables (knowledge, belief, attitudes, and opinions) were sufficiently reliable. Reliability analysis allows one to study the properties of measurement scales and the items that compose the scales (Tabachnick \& Fidell, 2007). Cronbach's alpha $(\alpha)$ reliability analysis procedure calculates a reliability coefficient that ranges between 0 and 1 . The reliability coefficient 
is based on the average inter-item correlation. Scale reliability is assumed if the coefficient is $\alpha \geq .70$. Results from the tests indicated that one variable construct exceeded the critical value (attitude $\alpha=.456$ ). No actions could be taken to increase Cronbach's alpha (e.g. removing survey items, reverse coding, etc.), therefore the violation of reliability for the dependent variable (attitude) was considered a limitation of the study. The remaining distributions did not violate the assumption of reliability and were considered sufficiently reliable. Displayed in Table 5 are summary statistics from the reliability analyses.

Table 5

Summary of Reliability Analysis for the Dependent Variables used to Evaluate Research Questions 1-3

\begin{tabular}{lrr}
\hline \multicolumn{1}{c}{ Dependent Variable } & \# of Items & Cronbach's Alpha \\
\hline Knowledge & 15 & .867 \\
Belief & 5 & .712 \\
Attitude & 5 & .456 \\
Opinion & 3 & .695 \\
\hline Note. Total $N=53$ & &
\end{tabular}

\section{Normality}

Before the research question was analyzed, basic parametric assumptions were assessed. That is, for the dependent variables (knowledge, belief, opinions, and attitudes) assumptions of normality, homogeneity of variance, homogeneity of variance-covariance, matrices, and multicollinearity were tested. To test if the distributions were normally distributed the skew and kurtosis coefficients were divided by the skew/kurtosis standard errors, resulting in z-skew/z-kurtosis coefficients. This technique was recommended by Tabachnick and Fidell (2007). Specifically, $z$-skew/z-kurtosis coefficients exceeding the 
critical range between -3.29 and $+3.29(p<.001)$ may indicate non-normality. Thus, based on the evaluation of the z-skew/z-kurtosis coefficients, no distributions were found to be significantly skewed or kurtotic. Therefore, the dependent variables were assumed to be normally distributed.

Table 6

Skewness and Kurtosis Statistics of Participants' Knowledge, Belief, Attitudes, and Opinions of Childhood Immunization by Whether they Provided Shots on Schedule

\begin{tabular}{|c|c|c|c|c|c|c|c|}
\hline \multirow[b]{2}{*}{ Variable } & \multirow[b]{2}{*}{$n$} & \multicolumn{3}{|c|}{ Skew } & \multicolumn{3}{|c|}{ Kurtosis } \\
\hline & & Skewness & $\begin{array}{l}\text { Std. } \\
\text { Error }\end{array}$ & z-skew & Kurtosis & $\begin{array}{l}\text { Std. } \\
\text { Error }\end{array}$ & z-kurtosis \\
\hline \multicolumn{8}{|c|}{ All Shots on Schedule } \\
\hline Knowledge & 32 & 0.532 & 0.414 & 1.285 & -0.901 & 0.809 & -1.114 \\
\hline Belief & 32 & 0.442 & 0.414 & 1.068 & -0.301 & 0.809 & -0.372 \\
\hline Attitude & 32 & -0.294 & 0.414 & -0.710 & -0.529 & 0.809 & -0.654 \\
\hline Opinion & 32 & 0.327 & 0.414 & 0.790 & 0.539 & 0.809 & 0.666 \\
\hline \multicolumn{8}{|l|}{ Some/No Shots on } \\
\hline Knowledge & 21 & -0.505 & 0.501 & -1.008 & 0.228 & 0.972 & 0.235 \\
\hline Belief & 21 & -0.714 & 0.501 & -1.425 & 0.313 & 0.972 & 0.322 \\
\hline Attitude & 21 & 0.932 & 0.501 & 1.860 & 3.179 & 0.972 & 3.271 \\
\hline Opinion & 21 & -1.425 & 0.501 & -2.844 & 0.367 & 0.972 & 0.378 \\
\hline
\end{tabular}

\section{Homogeneity of Variance}

Levene's Test of Equality of Error Variance was run to determine if the error variances of the dependent variables (knowledge, belief, attitudes, and opinions) were equal across levels of the independent variable (scheduled immunization, age, and gender). Results indicated that one distribution violated the assumption of homogeneity of variance (opinion $p<.001$ ). These results suggest that the error variances were not equally distributed across levels of the independent variable (received shots on schedule). Thus, non-parametric Kruskal-Wallis tests were conducted to affirm the 
results of the MANOVA analyses for the aforementioned dependent variable (opinion).

The remaining distributions (knowledge, belief, and attitude) did not violate the assumption of homogeneity $(p>.05)$. Displayed in Table 7are summary details of the Levene's tests for research questions 1-3.

Table 7

Summary of Levene's Tests for Research Questions $1-3$

\begin{tabular}{lrrrr}
\hline \multicolumn{1}{c}{ Variable } & F & df1 & df2 & Sig. $(p)$ \\
\hline Research Question 1 & & & & \\
$\quad$ Knowledge & 0.105 & 1 & 51 & 0.747 \\
Belief & 0.498 & 1 & 51 & 0.483 \\
Attitude & 0.232 & 1 & 51 & 0.632 \\
Opinion & 17.223 & 1 & 51 & $<.001$ \\
& & & & \\
Research Question 2 & & & & \\
Knowledge & 1.216 & 3 & 49 & 0.314 \\
Belief & 0.746 & 3 & 49 & 0.530 \\
Attitude & 0.526 & 3 & 49 & 0.667 \\
Opinion & 7.388 & 3 & 49 & $<.001$ \\
& & & & \\
Research Question 3 & & & & \\
Knowledge & 0.086 & 3 & 49 & 0.967 \\
Belief & 1.251 & 3 & 49 & 0.301 \\
Attitude & 0.220 & 3 & 49 & 0.882 \\
Opinion & 8.754 & 3 & 49 & $<.001$ \\
\hline
\end{tabular}

Note. Total $N=53$

\section{Homogeneity of Variance -Covariance Matrices}

To examine the assumption of homogeneity of variance-covariance matrices

Box's M Test of Equality of Covariance Matrices was conducted. The test was run to determine if the distributions of the dependent variables (knowledge, belief, attitudes, and opinions) were equal across the levels of the independent variables (scheduled immunization, age, and gender). The critical value determining violation of the assumption is $p<.001$. Results from the test found that the distributions were equal 
across the dependent variables. Therefore, the assumption of homogeneity of variancecovariance matrices was not violated. Displayed in Table 8 are summary statistics of the Box's M tests conducted for research questions 1-3.

Table 8

Summary of Box's M Tests Conducted for Research Questions 1-3

\begin{tabular}{crrrrr}
\hline Research Question & Box's M & \multicolumn{1}{c}{ df1 } & df2 & F & Sig. $(p)$ \\
\hline RQ1 & 23.049 & 10 & 8543.674 & 2.095 & 0.022 \\
RQ2 & 18.668 & 10 & 7855.218 & 1.683 & 0.079 \\
RQ3 & 38.522 & 20 & 6207.280 & 1.680 & 0.029 \\
\hline
\end{tabular}

Note. Total $N=53$

\section{Multicollinearity}

The assumptions of multicollinearity was tested by calculating correlations between dependent variables (knowledge, belief, attitudes, and opinions) using collinearity statistics (correlations, tolerance and variance inflation factor). Correlations between dependent variables did not exceed .80 . Additionally, tolerance was calculated using the formula $T=1-R^{2}$ and variance inflation factor (VIF) was the inverse of Tolerance (1 divided by T). Commonly used cut-off points for determining the presence of multicollinearity are $T<.10$ and $V I F$ $>10$. Results indicated that tolerance and VIF coefficients did not exceed the critical values. Therefore, the presence of multicollinearity was not assumed. Displayed in Table 9 are summary statistics of the correlation analysis conducted to test the assumption of multicollinearity.

Table 9

Correlations between Dependent Variables

\begin{tabular}{lrrrr}
\hline Dependent Variable & Knowledge & \multicolumn{1}{c}{ Belief } & \multicolumn{1}{c}{ Attitude } & \multicolumn{1}{c}{ Opinion } \\
\hline Knowledge & 1.000 & 0.703 & -0.253 & 0.463 \\
Belief & & 1.000 & -0.255 & 0.407
\end{tabular}


Note. Total $N=53$

Results of Hypothesis 1

Null Hypothesis $1\left(\mathrm{H}_{1}\right)$ : There is no difference in Amish parents

Knowledge, belief, attitudes, and opinions toward childhood immunizations between those who immunize their children according to the recommended schedule and those who do not.

Alternative Hypothesis $1\left(\mathrm{H} 1_{\mathrm{A}}\right)$ : There is a difference in Amish parents knowledge, belief, attitudes, and opinions toward childhood immunizations between those who immunize their children according to the recommended schedule and those who do not.

Multivariate analysis of variance (MANOVA) was used to determine if any significant differences in Amish parent's knowledge, belief, attitudes, and opinions toward childhood immunizations existed between those who immunize their children according to the recommended schedule and those who do not. Results indicated that there were significant multivariate differences between those who immunize their children according to the recommended schedule and those who do not on a model containing four dependent variables (knowledge, belief, attitudes, and opinions), Wilks' Lambda $=0.770, F(4,48)=3.586, p .=.012, \eta^{2}=.230$. Displayed in Table 10 are summary statistics of the MANOVA multivariate analysis. 
Table 10

Summary of MANOVA Multivariate Analysis for Hypothesis 1

\begin{tabular}{lrrrrrr}
\hline \multicolumn{1}{c}{ Model } & $\begin{array}{c}\text { Wilks' } \\
\text { Lambda }\end{array}$ & \multicolumn{1}{c}{ F } & Hypothesis df & Error df & Sig. $(p)$ & $\begin{array}{r}\text { Partial Eta } \\
\text { Squared }\left(\eta^{2}\right)\end{array}$ \\
\hline Intercept & 0.008 & 1522.731 & 4 & 48 & $<.001$ & 0.992 \\
Shots on Schedule & 0.770 & 3.586 & 4 & 48 & 0.012 & 0.230 \\
\hline
\end{tabular}

Note. . Dependent variables $=$ knowledge, belief, attitudes, and opinions; Total $N=53$

Results from the between-subjects effects indicated that there were significant differences on three of the four dependent variables between those that provided their children with the recommended immunization shots on schedule and those that did not (knowledge $p=.001$, belief $p=.020$, and opinion $p=.027$ ). That is, those that provided their children with shots on time had significantly higher knowledge $(M=5.046)$, belief $(M=4.163)$, and opinion $(M=4.875)$ scores than those that did not provide shots on schedule (knowledge $M=4.479$, belief $M=3.571$, and opinion $M=4.349$ ). However, results from the non-parametric Kruskal-Wallis test indicated that there were no significant differences in participants' opinion scores between leader types—see Table 17 in Appendix D. There were no significant differences in participants' attitudes toward childhood immunization between those that provided shots on schedule $(M=2.338)$ and those who $\operatorname{did} \operatorname{not}(M=2.400)$. Thus, the null hypothesis for research question 1 was partially rejected in favor of the alternative hypothesis since two of the four dependent variables were found to be significantly different across levels of the independent variable. Displayed in Table 11 is a model summary of the MANOVA tests of betweensubjects' effects conducted for research question 1. Additionally, means plots of participants' knowledge, belief, attitudes, and opinions toward childhood immunizations by whether participants' provided immunization shots on schedule are displayed in 
Table 11

Model Summary of Tests of Between-subjects Effects for Research Question 1

\begin{tabular}{|c|c|c|c|c|c|c|}
\hline Dependent Variable & $\begin{array}{l}\text { Type III Sum } \\
\text { of Squares }\end{array}$ & df & $\begin{array}{l}\text { Mean } \\
\text { Square }\end{array}$ & $\mathrm{F}$ & Sig. $(p)$ & $\begin{array}{c}\text { Partial Eta } \\
\text { Squared }\left(\eta^{2}\right)\end{array}$ \\
\hline \multicolumn{7}{|l|}{ Corrected Model } \\
\hline Knowledge & 4.069 & 1 & 4.069 & 13.747 & 0.001 & 0.212 \\
\hline Belief & 4.430 & 1 & 4.430 & 5.755 & 0.020 & 0.101 \\
\hline Attitude & 0.050 & 1 & 0.050 & 0.118 & 0.733 & 0.002 \\
\hline Opinion & 3.505 & 1 & 3.505 & 5.216 & 0.027 & 0.093 \\
\hline \multicolumn{7}{|l|}{ Intercept } \\
\hline Knowledge & 1150.380 & 1 & 1150.380 & 3886.977 & $<.001$ & 0.987 \\
\hline Belief & 758.392 & 1 & 758.392 & 985.229 & $<.001$ & 0.951 \\
\hline Attitude & 284.572 & 1 & 284.572 & 675.817 & $<.001$ & 0.930 \\
\hline Opinion & 1078.826 & 1 & 1078.826 & 1605.373 & $<.001$ & 0.969 \\
\hline \multicolumn{7}{|l|}{ Shots on Schedule } \\
\hline Knowledge & 4.069 & 1 & 4.069 & 13.747 & 0.001 & 0.212 \\
\hline Belief & 4.430 & 1 & 4.430 & 5.755 & 0.020 & 0.101 \\
\hline Attitude & 0.050 & 1 & 0.050 & 0.118 & 0.733 & 0.002 \\
\hline Opinion & 3.505 & 1 & 3.505 & 5.216 & 0.027 & 0.093 \\
\hline \multicolumn{7}{|l|}{ Error } \\
\hline Knowledge & 15.094 & 51 & 0.296 & & & \\
\hline Belief & 39.258 & 51 & 0.770 & & & \\
\hline Attitude & 21.475 & 51 & 0.421 & & & \\
\hline Opinion & 34.272 & 51 & 0.672 & & & \\
\hline \multicolumn{7}{|l|}{ Total } \\
\hline Knowledge & 1251.187 & 53 & & & & \\
\hline Belief & 861.560 & 53 & & & & \\
\hline Attitude & 317.280 & 53 & & & & \\
\hline Opinion & 1192.000 & 53 & & & & \\
\hline \multicolumn{7}{|l|}{ Corrected Total } \\
\hline Knowledge & 19.162 & 52 & & & & \\
\hline Belief & 43.688 & 52 & & & & \\
\hline Attitude & 21.525 & 52 & & & & \\
\hline Opinion & 37.778 & 52 & & & & \\
\hline
\end{tabular}

\section{Results of Hypothesis 2}

Null Hypothesis $2\left(\mathrm{H} 2_{0}\right)$ : There is no difference in Amish parent's knowledge, belief, attitudes, and opinions toward childhood immunizations between those who 
immunize their children according to the recommended schedule and those who do not and the difference is not affected by age group.

Alternative Hypothesis $2(\mathrm{H} 2 \mathrm{~A})$ : There is a difference in Amish parents knowledge, belief, attitudes, and opinions toward childhood immunizations between those who immunize their children according to the recommended schedule and those who do not and the difference is affected by age group.

Multivariate analysis of variance (MANOVA) was used to determine if any significant differences in Amish parent's knowledge, belief, attitudes, and opinions toward childhood immunizations existed between those who immunize their children according to the recommended schedule and those who do not, and whether the difference depended on age groups. Results indicated that age did not have a significant effect on the differences between those who immunize their children according to the recommended schedule and those who do not within a model containing four dependent variables (knowledge, belief, attitudes, and opinions), Wilks' Lambda $=0.967, F(4,46)=$ $0.387, p .=.817, \eta^{2}=.033$. Thus, the null hypothesis for research question 2 was retained. Displayed in Table 12 are summary statistics of the MANOVA multivariate analysis. Furthermore, a model summary of the individual between-subject effects is displayed in Appendix F.

Table 12

Summary of MANOVA Multivariate Analysis for Hypothesis 2

\begin{tabular}{lrrrrrrr}
\hline \multicolumn{1}{c}{ Model } & $\begin{array}{c}\text { Wilks' } \\
\text { Lambda }\end{array}$ & \multicolumn{1}{c}{ F } & $\begin{array}{r}\text { Hypothesis } \\
\text { df }\end{array}$ & Error df & Sig. $(p)$ & $\begin{array}{r}\text { Partial Eta } \\
\text { Squared }\left(\eta^{2}\right)\end{array}$ \\
\hline Wilks' Lambda & 0.031 & 358.140 & & 4 & 46 & $<.001$ & 0.969 \\
Shots on Schedule & 0.962 & 0.452 & & 4 & 46 & 0.770 & 0.038 \\
Gender & 0.969 & 0.365 & 4 & 46 & 0.832 & 0.031 \\
Shots on Schedule * Gender & 0.967 & 0.387 & 4 & 46 & 0.817 & 0.033 \\
\hline
\end{tabular}


Note. Dependent variables $=$ knowledge, belief, attitudes, and opinions, total $N=53$

\section{Results of Hypothesis 3}

Null Hypothesis $3\left(\mathrm{H}_{3}\right)$ : There is no difference in Amish parent's knowledge, belief, attitudes, and opinions toward childhood immunizations between those who immunize their children according to the recommended schedule and those who do not and the difference is not affected by gender.

Alternative Hypothesis $3(\mathrm{H} 3 \mathrm{~A})$ : There is a difference in Amish parents knowledge, belief, attitudes, and opinions toward childhood immunizations between those who immunize their children according to the recommended schedule and those who do not and the difference is affected by gender.

Multivariate analysis of variance (MANOVA) was used to determine if any significant differences in Amish parent's knowledge, belief, attitudes, and opinions toward childhood immunizations existed between those who immunize their children according to the recommended schedule and those who do not, and whether the difference depended on gender. Results indicated that gender did not have a significant effect on the differences between those who immunize their children according to the recommended schedule and those who do not within a model containing four dependent variables (knowledge, belief, attitudes, and opinions), Wilks' Lambda $=0.952, F(4,46)=$ $0.577, p .=.681, \eta^{2}=.048$. Thus, the null hypothesis for research question 3 was retained. Displayed in Table 3 are summary statistics of the MANOVA multivariate analysis. Furthermore, a model summary of the individual between-subject effects is displayed in Appendix D. 
Table 13

Summary of MANOVA Multivariate Analysis for Hypothesis 3

\begin{tabular}{lrrrrrr}
\hline \multicolumn{1}{c}{ Model } & $\begin{array}{c}\text { Wilks' } \\
\text { Lambda }\end{array}$ & F & $\begin{array}{c}\text { Hypothesis } \\
\text { df }\end{array}$ & Error df & Sig. $(p)$ & $\begin{array}{r}\text { Partial Eta } \\
\text { Squared }\left(\eta^{2}\right)\end{array}$ \\
\hline Intercept & 0.016 & 688.824 & 4 & 46 & $<.001$ & 0.984 \\
Shots on Schedule & 0.896 & 1.339 & 4 & 46 & 0.270 & 0.104 \\
Age & 0.931 & 0.846 & 4 & 46 & 0.504 & 0.069 \\
Shots on Schedule * Age & 0.952 & 0.577 & 4 & 46 & 0.681 & 0.048 \\
\hline
\end{tabular}

\section{Summary}

Chapter 4 provides information on the data analysis and results of the study. The results of this study may add to the literature providing information discussing underimmunization among Amish communities.

The study sample consisted of 84 Amish individuals who reside in Ashtabula County Ohio. Individuals voluntarily filled out and returned the Amish Immunization Questionnaire.

The findings from this study demonstrate significant difference on three of the four dependent variables between Amish individuals that provided their children with the recommended immunizations according to the recommended schedule. The findings also demonstrate that gender or age of the Amish individual did not have any significant effect on the differences between those who provided their children with the recommended immunizations according to the recommended schedule and those that did not. Chapter 5 will discuss the results of the findings in more detail and provide conclusions and recommendations. 
Chapter 5: Discussion, Conclusions, and Recommendations

\section{Introduction}

Globally vaccines are viewed as a cost-effective method to prevent disease and death (CDC, 2000). Childhood immunization has proven to be a vital component of health promotion. Statistics reported in the year 2000 indicated the United States had achieved the lowest rates of vaccine-preventable diseases and the highest rates of immunization ever recorded (CDC, 2000). Unfortunately, in the past ten years the United States had recognized an increase in the numbers of certain vaccine preventable diseases, and a decrease in rates of certain immunizations. Multiple outbreaks of vaccinepreventable diseases including pertussis, rubella, measles, varicella, and Hib have been reported in under-immunized Amish communities (CDC, 2006). Understanding select populations, such as the Amish, is crucial for prevention of disease outbreaks because under immunized populations are suspected of being reservoirs for infection. This study was conducted in attempt to gain information regarding the knowledge, beliefs, opinions, and attitudes that Amish parents in Ashtabula County have about immunizing their children according to the recommended immunization schedule.

To determine if difference existed among the dependent variables, knowledge, belief, attitude, and opinion between Amish parents who had their children receive all recommended immunizations according to the recommended schedule and those who did not have their children receive all recommended immunizations according to the recommended schedule a correlational study was conducted. 


\section{Review of Findings}

Findings demonstrated that a high percentage, $97.6 \%$ of respondents accept some immunizations for their children. Fifty eight percent of parents reported they accept all immunizations for their children and $39.3 \%$ of parents reported that they accepted some immunizations for their children; although many do not have their children immunized according to the recommended immunization schedule. Only two of the respondents reported not accepting any immunizations for their children. Findings also showed that immunization adherence was affected by Amish parents knowledge, beliefs, and opinions. As evidenced by findings, Amish from the Old Order who mostly adhere to the immunization schedule were more likely to have more accurate knowledge of the benefits and risks of immunizing their child.

Findings also demonstrated that Amish parents who had more positive beliefs regarding the safety factors and the effect immunizations have on a child's immune system were more likely to have their children immunized according to the recommended schedule than parents that did not have positive beliefs based on the results of the questionnaire. Based on the results of the study more parents had concerns pertaining to safety factors and potential adverse effects from immunizations than general knowledge factors relating to providing their children with immunizations. More parents indicated a belief that having too many immunizations given at the same time or at a young age could be harmful to a child.

As evidenced by the study findings, parents with knowledge of the benefits of immunizations may still not have their children immunized according to the 
recommended schedule due to the fact they believe the recommended schedule could be detrimental to a child. Overall parents may demonstrate having knowledge that the benefits of immunizations outweigh the risks of immunizations; however, they may still believe they can take actions to reduce their perceived risks, such as following an alternative immunization schedule. Study finding demonstrated that parents who had opinions based on the knowledge that immunizations can be provided free of charge and home visits can be made by the health department nurses to provide free immunizations had their children immunized according to the recommended immunization schedule more often than parents that did not have this knowledge to base their opinions on.

Study results from the between-subjects effects indicated that there were significant differences on three (knowledge, belief, opinion) of the four dependent variables between those that provided their children with the recommended immunizations on schedule and those that did not; however, there was not a significant difference on the attitude variable. Religious attitudes did not have a significant effect on Amish parent's decisions to have their children immunized according to the recommended schedule or not according to the recommended schedule.

The information gained in this study demonstrated some of the same findings found in previous studies; however, some of the information varied from findings of previous studies done. A study done by Fry et al., 2009 demonstrated Amish parents reported various reasons for failure to immunize their children. More than half of the parents reported they did not believe that immunizations were a priority compared with other activities that were required in their daily lifestyle. Eleven percent of parents 
reported fear of immunization side effects and 22\% reported philosophical reasons for not immunizing their children. Only $6 \%$ reported religious objections as the reason for not immunizing their children. Over $70 \%$ of parents reported that they would accept at least some vaccines if they didn't have to travel so far to receive them. (Fry et al., 2001).

Similar to the finding in the 2009 study conducted by Fry et al., Amish parents in Ashtabula County did not report religious reasons as a significant factor for not immunizing their children according to the recommended schedule. Unlike findings from the study by Fry et al. fear of adverse effects from immunizations was the most frequently reported reason Amish parents in Ashtabula County provided for not having their children immunized according to the recommended schedule. Only $11 \%$ of the parents in the study by Fry et al., reported fear of adverse reaction from immunizations as a reason for not following the recommended schedule. In the study conducted by Fry et al., over $70 \%$ of parents reported the distance they had to travel to receive immunizations as a barrier.

Access to immunizations due to travel distance was not among the top reported reasons Amish parents in Ashtabula County reported for failure to have their children immunized according to the recommended schedule; however, parents who reported not having knowledge that public health nurses in Ashtabula County could provide home visits to provide free immunizations, did include this factor as one reason for noncompliance.

In another previous study conducted among an Amish population the authors stated that although the Amish church does not specifically prohibit immunizations; they 
are not encouraged. Amish cultural practices seek to avoid dependence on government assistance; therefore, many consider accepting free immunizations a form of assistance from the government (Yoder \& Dworkin, 2006). Amish parents in Ashtabula County did not report a concern over receiving free immunizations from the health department. In fact some parents provided comments at the end of the questionnaire stating home visits to provide immunizations for their children were greatly appreciated.

A study conducted in Holmes County Ohio, one of the largest Amish communities in the world, demonstrated that more Amish parents reported accepting immunizations than the authors expected; however, most of the parents reported they only permitted certain immunizations for their children. The study also demonstrated that decisions regarding immunizations were not strictly influenced by religious beliefs, and many parents reported decisions to exempt certain immunizations on the basis of ethical values. Additionally parents reported concern over adverse effects of immunizations as a major barrier (Wenger et al.2011).

Amish parents in Ashtabula County reported concern about adverse effects and the ability of a child to tolerate immunizations as the major barrier. Based on the results of this study religious doctrine does not affect decisions of Old Order Amish parents in Ashtabula County regarding their decisions to immunize their children according to the recommended schedule. Accessibility was reported as a barrier by some parents; although it was not reported as a major barrier.

Wenger et al., 2011 reported the results of their study indicated that concerns about immunizations among the Amish population are similar to reported concerns of 
non-Amish parents in the United States. Adverse effects and ability for children to tolerate giving too many immunizations at the same time have been reported as major barriers in studies conducted among non-Amish populations (Wenger et al.,2011).

Research shows that significant health benefits have resulted due to the successful immunization of children and adults in the United States. A reduction in morbidity and mortality, cost-savings to the health system, and overall benefits to society have resulted from providing immunizations. Although progress has been made in increasing the number of individuals who are protected through immunization there are certain groups in the United States that remain under-immunized. Amish communities do not accept immunizations as widely as non-Amish communities. Health care practices vary considerably among Amish communities. (Diekema, 2012).

Attitudes of the Amish toward preventive health care practices may partly contribute to their decision not to utilize preventive practices such as immunizations; however, religious attitudes did not significantly impact Amish parent's immunization adherence in the findings of this study. As evidenced by findings, Amish from the Old Order who mostly adhere to the immunization schedule are more likely to have a better knowledge, and beliefs and opinions based on accurate knowledge.

\section{Discussion}

The aim of the study was to gain a better understanding of the reasons for the low rates of immunization coverage among the Amish community in Ashtabula County. The purpose of the study was to determine if knowledge, beliefs, opinions, and attitudes affected Amish parent's immunization adherence and if, age, gender, or Amish order, had 
any impact on these.

The PEN-3 theoretical model was used to support the four research questions. The PEN acronym includes perceptions, enablers, and nurturers. Perceptions pertain to knowledge, beliefs, attitudes, and values that may facilitate or hinder motivation for behavior. Enablers include societal or systemic forces that may augment or hinder health behaviors. Nurturers are reinforcing factors that an individual may receive from significant others, such as family, peers, or religious leaders (Airhihenbuwa, 1995).

Findings from Hypothesis 1 supported the fact, that Amish parent's immunization adherence was affected by their knowledge, beliefs, and opinions toward immunization.

\section{Limitations}

The study was limited in many ways. Limitations are aspects of the study that the researcher cannot control. Successful contact with all Amish families was not possible to obtain. There is not an Amish Directory available for the county; therefore, information was obtained through the main county directory and Amish community bishops and elders. Many, but not all Amish families are listed in the main directory. Additionally, not all Amish parents in the community were willing to complete the questionnaire. Although it is known that a group of Swartzentruber Amish reside in Ashtabula County no information was able to be obtained from this group regarding their reason for not accepting immunizations. Eleven Amish residents returned surveys not filled out. The questionnaires were not completed; however, nine of the questionnaires had some form of written communication at the top of the returned questionnaire stating that the individual did not believe in completing surveys or in taking immunizations. 


\section{Conclusions}

Findings from the study support hypothesis 1and revealed a link between knowledge, beliefs, and opinions toward immunization and immunization adherence. As such, the null hypothesis associated with Research Question 1 was rejected in favor of the alternative. However, the null hypotheses associated with Research Question 2, and 3 were retained; that is, age and gender did not affect the relationship between knowledge, beliefs, opinions, and attitudes toward immunization and immunization adherence.

The results of this study may add to the current literature discussing reasons for lower immunization rates among Amish populations. As discussed in the literature review previous studies suggest there are a variety of factors that affect Amish parent's decisions regarding childhood immunizations. This study supports the fact that more Amish parents in Ashtabula County report that decisions about immunizations are based on philosophical reasons rather than religious attitudes or access issues. Knowledge, beliefs, and opinions regarding vaccine safety, and concern over placing stress on the child's immune system represent the major barriers to immunizing according to the recommended schedule reported by parents in Ashtabula County.

\section{Recommendations}

Efforts of health care providers working with Amish families in Ashtabula County should focus on redirection of parental misconceptions regarding vaccine safety concerns. Different approaches may be required to address misconceptions about immunizations with the Amish population than are used with the general population. 


\section{Recommendations for practice}

Health practitioners should consider using Amish parents from the old order who mostly adhere to the immunization schedule as proxies to distribute the message that herd immunization needs to be obtained. In addition, heath practitioners should consider using Amish parents from the old order who mostly adhere to the immunization schedule as ambassadors to further educate those that do not adhere to immunization schedules.

Health practitioners should realize that age or gender does not contribute to explaining knowledge, beliefs, opinions or attitudes toward immunization. Rather, both genders and all age groups generally retain similar knowledge, beliefs and opinions. For example, concentrating educational resources on just Amish males or females may not likely affect knowledge, beliefs, and opinions toward immunization at the level needed to change outcomes.

\section{Recommendations for further research}

Findings from the study revealed that immunization adherence was related to knowledge, beliefs, opinions, and attitudes toward immunizations. The study was quantitative, which provided a means to discover this relationship from a non-bias position. That is, the researcher did not directly interact with respondents nor interpret findings from semantic phrases. However, although findings did fill the gap in the literature, a better understanding of the complex dynamics that affect knowledge, beliefs and opinions may be necessary to fully understand the demonstrative problem that currently exists in the Amish community. For example, applying findings from this study, a multi-case, qualitative study could be conducted to uncover the emotional component 
behind Amish feelings that drive beliefs and opinions toward immunization.

In addition, a longitudinal quantitative investigation could be conducted to examine differences in knowledge, beliefs, opinions and attitudes about immunization across time in Old Order Amish parents. This information may provide researchers and practitioners with a better understanding about how these may be changing across time.

Finally, researchers should investigate knowledge, beliefs, opinions, and attitudes about immunization in other sects within the Amish community. This information may uncover differences in knowledge, beliefs, opinions and attitudes between groups and facilitate program development and targeted action to mitigate immunization rates.

\section{Implications for Social Change}

Amish communities have persistently low childhood immunization rates.

Findings from the study support hypothesis 1 and revealed a link between knowledge, beliefs, and opinions of Amish parents toward immunization and immunization adherence. This study can contribute to social change, by providing health care providers in Ashtabula County with valuable information for developing programs to educate parents of Amish children on the importance of childhood immunizations, while addressing their concerns.

Programs will need to be developed to provide parents with accurate knowledge of the benefits and risks of immunizations and address concerns relating to the fear parents reported relating to potential adverse reactions of immunizations. Providing Amish parents with appropriate educational programs to increase their knowledge may result in more positive beliefs about immunizations and increase parents opinions of the 
importance of having their children immunized according to the recommended schedule. Immunizing children according to the recommended schedule can help keep Amish communities free of vaccine preventable disease

Findings from this study did not support Hypothesis 2 and 3. Age and gender were not found to make a difference in the knowledge, beliefs, opinions and attitudes of Amish parents relating to immunizations. In developing educational programs health practitioners should be aware that age or gender does not contribute to Amish parents knowledge, beliefs, opinions or attitudes toward immunization; therefore, health practitioners do not need to concentrate resources on those factors as it is not likely to affect knowledge, beliefs, and opinions toward immunization at the level needed to change outcomes.

\section{Summary}

Significant health benefits have resulted due to the successful immunization of children and adults in the United States. Although significant progress has been made in increasing the number of individuals protected, there remain certain groups in the United States that remain under-immunized. The Amish population is one of these groups. (Wenger, McManus, Bower, \& Langkemp, 2011). Information gained from this study can provide health professionals working with Amish populations with reasons parents reported for non-compliance with the recommended immunization schedule. This information may assist health professionals in providing education to Amish parents.

Chapter 5 discussed the results of the study investigating reasons Amish parents in Ashtabula County provided for non-compliance with the recommended immunization 
schedule. It also provided recommendations for addressing parental concerns relating to childhood immunizations. Additionally this chapter discussed recommendations for future research that could be conducted to provide more insight into understanding Amish views regarding immunizations. 


\section{References}

American Academy of Pediatrics, (2013). Recommended immunization schedules.

Available from www2.aap.org/immunization/izschedule

Advisory Committee on Immunization Practices. (2014). Retrieved from

www.cdc.gov/vaccine/acip

Alexander, J., Ehresmann, K., Seward, J., Wax, G., Harriman, K., Fuller, S., \& Cebelinski, (2009). Transmission of imported vaccine-derived poliovirus in an under-vaccinated community in Minnesota. Journal of Infectious Diseases, 1119, 391-7.1119.

Amish Studies, (2014). Elizabethtown College. Retrieved from www2.etown.edu/amsihstudies

Ashtabula County Health Department, (2013). Annual report. Retrieved from ashtabulacountyhealth.com

Centers for Disease Control and Prevention. (1979, May 25). Poliomyelitis - United States, Canada. Morbidity and Mortality Weekly Reports, 46(RR-3):1-25.

Centers for Disease Control and Prevention. (2000). National, state, and urban area vaccination coverage level among children-United States. Morbidity and Mortality Weekly Reports, 50(30):637-641.

Centers for Disease Control and Prevention. (2006). Pertussis outbreak in an Amish community. Morbidity and Mortality Weekly Reports, 55(30):817-82.

Centers for Disease Control and Prevention (2006). Smallpox: $30^{\text {th }}$ anniversary of global eradication. Available at http://www.cdc.gov.Features/Smallpox Eradication 
Centers for Disease Control and Prevention. (2008, May 9). Measles-United States January 1-April 25, 2008. Morbidity and Mortality Weekly Reports, 57(18), 494495.

Centers for Disease Control and Prevention. (2009). Invasive Haemophilus influenza type $\mathrm{b}$ disease in five young children - Minnesota, 2008. Morbidity and Mortality Weekly Reports, 58(3), 58-60.

Centers for Disease Control and Prevention (2011). Ten great public health achievements United States. 2001-2010. Morbidity Mortality Weekly Report, 60(19), 619-623.

Center for Disease Control and Prevention. (2012, August 24). Vaccination coverage among children in kindergarten - United States, 2011-2012 school year. Morbidity and Mortality Weekly Reports.

Centers for Disease Control and Prevention. (2013). Advisory Committee on Immunization Practices. Retrieved from http://www.cdc.gov/vaccines/acip/about.html. Accessed April 26, 2014. Centers for Disease Control and Prevention. (2014). Recommended immunization schedule for persons aged 0-18 years-United States. Retrieved from http://www.cdc.gov/vaccines/schedules/downloads/child/018yrs-schedule.pdf. Accessed March 25, 2014.

Chinn, P. \& Kramer, M. (2008). Integrating theory and knowledge development in nursing ( $7^{\text {th }}$ Ed). St. Louis, MO: Mosby Elsevier.

Cowdery, J., Parker, S., \& Thompson, A. (2010). Application of the PEN - 3 model in a diabetes prevention intervention. Journal of Health Disparities Research and 
Practice, 4, 1-3.

Creswell, J. W. (1998). Qualitative inquiry and research design: Choosing among five approaches. ( $3^{\text {rd }}$ ed). Thousand Oaks, CA: Sage Publications.

Diekema, D. (2012). Improving childhood vaccination rates. New England Journal of Medicine. 366, 3942 doi:10.10561 NEJMp1113008

Fry, A., Lurie, P., Gidley, M., Schmink, S, Lingappa, J., Fischer, M., \& Rosenstein, N. (2001). Haemophilus influenza Type B disease among Amish children in Pennsylvania: Reasons for persistent disease. American Academy of Pediatrics, $108(4)$

Henderson, J. \& Anbar, R. (2009). Care for Amish and Mennonite children with cystic fibrosis: Case series. BMC Pediatrics, (9)4.

Imdad, A., Tserenpuntsag, B., Blog, D., Halsey, N., Easton, D., \& Shaw, J. (2013). Religious exemptions for immunization and risks of pertussis in New York State, 2000-2011. Pediatrics, 132(1), 37-43.

Jackson, B., Payton, T., Horst, G., Halpin, T., Mortensen, B. (1993). An epidemiologic investigation of a rubella outbreak among the Amish of northeast Ohio. Public Health Report, 108(4), 436-439.

Jacobson v. Massachusetts, 197 U.S. 11 (1905)

Medina-Marino, A., Reynolds, D., Finley, B., Hays, S., Jones, J., \& Soyemi, K. (2013). Communication and mass vaccination strategies after pertussis outbreak in rural Amish communities. Journal of Rural Health 2103, 29(4), 413-9. 
Ohio Department of Health Office of Public Affairs (2014). Measles outbreak confirmed. Retrieved from www.odh.ohio.gov/features/odhfeatures/measles\%202014.aspx

Ohio State University Working with the Amish. Retrieved from http://ohioline.osu.edu/hyg-fact/5000/5236.html

Omer, S., Salmon, D., Orenstein, W., DeHart, P., \& Halsey, N. (2009). Vaccine refusal, mandatory immunization and the risks of vaccine preventable disease. New England Journal of Medicine, 360, 1981-1988.

Opel, Diekema, Lee, \& Marcuse. (2009) Social marketing as a strategy to increase immunization rates. Pediatric \& Adolescent Medicine, 163(5), 432-437.

Smith, P., Chu, S., \& Barker, L. (2004). Children who have received no vaccines: who they are and where do they live: Pediatrics, 114(1), 187-195.

Stanhope, M., \& Lancaster, J. (2012). Public Health Nursing: Population Centered Health Care in the Community ( $8^{\text {th }}$ Ed.). St. Louis, MO: Mosby -Elsevier.

Tabachnick, B., C. \& Fidell, L., S. (2007). Using multivariate statistics ( $5^{\text {th }}$ edition). Boston, MA: Pearson.

United States Department of Health and Human Services, Healthy People 2020. (2011, June 10). Immunization and infectious diseases. Retrieved from http: healthypeople.org 
Volden, C., Langemo, D., Adamson, M. and Oechsle, L. (1990). The relationship of age, gender, and exercise practice to measures of health, life-style, and self-esteem. Applied Nursing Research, 3(1), 20-6.

Wenger, O., McManus, M., Bower, J. and Langkamp, D. (2011). Under-immunization in Ohio's Amish: Parental fears are a greater obstacle than access to care. Pediatrics, 128(1) 79-85 doi: 10.1542/peds.2009-2599.Epub 2011 Jun 27.

Weyer, S., Hstey, J., Rathbun, L., Armstrong, V., Reed, S., Ronyak, J., \& Savrin, C., (2003). A look into the Amish culture: What should we learn? Journal of $W$ Transcultural Nursing 14:139

Wisconsin v. Yoder, 406 U.S. 205 (1905)

World Health Organization. Immunizations. Retrieved from www.who.int/topics/immunization

Yoder, J. and Dworkin, M. (2006). Vaccination usage among an old-order Amish in Illinois. Pediatric Infectious Diseases, 25(12), 1182-3.

Zhou, F., Shefer, A., Wenger, J., Messonnier, M., Yan Wang, L., Lopez, A. (2009). Economic evaluation of the routine childhood immunization program in the United States, Pediatrics. 2014; 133(4), 1-9. 


\section{Appendix A: Amish Immunization Questionnaire}

1. What is your gender?

1. Male

2. Female

2. What is your age?

1. $18-25$

2. $26-35$

3. $36-45$

4. $46-55$

5. $55+$

3. What is your Amish order?

1. Old order Amish

2. New order Amish

3. Swartzentruber

4. Other

4. My child/children have had:

1. All the recommended shots according to the schedule

2. Some of the recommended shots according to the schedule

3. None of the recommended shots according to the schedule

5. Religious Attitudes toward Immunization

a. The minister/bishop in my community disagrees with giving shots.

\begin{tabular}{cccccc}
\hline $\begin{array}{c}\text { Strongly } \\
\text { Disagree }\end{array}$ & Disagree & $\begin{array}{c}\text { Slightly } \\
\text { disagree }\end{array}$ & $\begin{array}{c}\text { Slightly } \\
\text { Agree }\end{array}$ & Agree & $\begin{array}{c}\text { Strongly } \\
\text { agree }\end{array}$ \\
\hline 1 & 2 & 3 & 4 & 5 & 6 \\
\hline
\end{tabular}

b. Other families in my community do not give shots. 


\begin{tabular}{cccccc}
\hline $\begin{array}{c}\text { Strongly } \\
\text { Disagree }\end{array}$ & Disagree & $\begin{array}{c}\text { Slightly } \\
\text { disagree }\end{array}$ & $\begin{array}{c}\text { Slightly } \\
\text { Agree }\end{array}$ & Agree & $\begin{array}{c}\text { Strongly } \\
\text { agree }\end{array}$ \\
\hline 1 & 2 & 3 & 4 & 5 & 6 \\
\hline
\end{tabular}

c. If I give my children shots, it means I'm not putting faith in God to take care of them.

\begin{tabular}{cccccc}
\hline $\begin{array}{c}\text { Strongly } \\
\text { Disagree }\end{array}$ & Disagree & $\begin{array}{c}\text { Slightly } \\
\text { disagree }\end{array}$ & $\begin{array}{c}\text { Slightly } \\
\text { Agree }\end{array}$ & Agree & $\begin{array}{c}\text { Strongly } \\
\text { agree }\end{array}$ \\
\hline 1 & 2 & 3 & 4 & 5 & 6 \\
\hline
\end{tabular}

d. I believe that god would not want you to give shots to your child.

\begin{tabular}{cccccc}
\hline $\begin{array}{c}\text { Strongly } \\
\text { Disagree }\end{array}$ & Disagree & $\begin{array}{c}\text { Slightly } \\
\text { disagree }\end{array}$ & $\begin{array}{c}\text { Slightly } \\
\text { Agree }\end{array}$ & Agree & $\begin{array}{c}\text { Strongly } \\
\text { agree }\end{array}$ \\
\hline 1 & 2 & 3 & 4 & 5 & 6 \\
\hline
\end{tabular}

e. I feel giving shots disagrees with my faith or spiritual beliefs in some way.

\begin{tabular}{cccccc}
\hline $\begin{array}{c}\text { Strongly } \\
\text { Disagree }\end{array}$ & Disagree & $\begin{array}{c}\text { Slightly } \\
\text { disagree }\end{array}$ & $\begin{array}{c}\text { Slightly } \\
\text { Agree }\end{array}$ & Agree & $\begin{array}{c}\text { Strongly } \\
\text { agree }\end{array}$ \\
\hline 1 & 2 & 3 & 4 & 5 & 6 \\
\hline
\end{tabular}

6. Based on the immunization schedule (depicted below), I have ensured that my child/children received all recommended shots on time. (starting at birth then at two months of age)

\begin{tabular}{cccccc}
\hline $\begin{array}{c}\text { Strongly } \\
\text { Disagree }\end{array}$ & Disagree & $\begin{array}{c}\text { Slightly } \\
\text { disagree }\end{array}$ & $\begin{array}{c}\text { Slightly } \\
\text { Agree }\end{array}$ & Agree & $\begin{array}{c}\text { Strongly } \\
\text { agree }\end{array}$ \\
\hline 1 & 2 & 3 & 4 & 5 & 6 \\
\hline
\end{tabular}




\section{immunization schedule}

\begin{tabular}{|c|c|c|c|c|c|c|c|}
\hline & Birth & $2 m$ & $4 m$ & $6 m$ & $12 \mathrm{~m}$ & $18 \mathrm{~m}$ & 4 Years \\
\hline HepB & 0 & 0 & & 0 & & & \\
\hline Rotavirus & & O & O & O & & & \\
\hline DTaP & & O & O & O & O & & 0 \\
\hline Hib & & O & O & O & ○ & & \\
\hline PCV & & O & O & O & P & & \\
\hline Polio & & O & O & O & & & O \\
\hline MMR & & & & & O & & O \\
\hline Varicella & & & & & O & & O \\
\hline HepA & & & & & O & O & \\
\hline Influenza & \multicolumn{7}{|c|}{ Every year beginning at 6 months of age } \\
\hline
\end{tabular}

7. Following immunization recommendations significantly reduces the likelihood of preventable disease outbreaks in my community.

\begin{tabular}{cccccc}
\hline $\begin{array}{c}\text { Strongly } \\
\text { Disagree }\end{array}$ & Disagree & $\begin{array}{c}\text { Slightly } \\
\text { disagree }\end{array}$ & $\begin{array}{c}\text { Slightly } \\
\text { Agree }\end{array}$ & Agree & $\begin{array}{c}\text { Strongly } \\
\text { agree }\end{array}$ \\
\hline 1 & 2 & 3 & 4 & 5 & 6 \\
\hline
\end{tabular}

8. Cultural Influence

a. My parents assured that I received all my baby shots.

\begin{tabular}{cccccc}
\hline $\begin{array}{c}\text { Strongly } \\
\text { Disagree }\end{array}$ & Disagree & $\begin{array}{c}\text { Slightly } \\
\text { disagree }\end{array}$ & $\begin{array}{c}\text { Slightly } \\
\text { Agree }\end{array}$ & Agree & $\begin{array}{c}\text { Strongly } \\
\text { agree }\end{array}$ \\
\hline 1 & 2 & 3 & 4 & 5 & 6 \\
\hline
\end{tabular}

b. Most other families in my community were diligent.

\begin{tabular}{cccccc}
\hline $\begin{array}{c}\text { Strongly } \\
\text { Disagree }\end{array}$ & Disagree & $\begin{array}{c}\text { Slightly } \\
\text { disagree }\end{array}$ & $\begin{array}{c}\text { Slightly } \\
\text { Agree }\end{array}$ & Agree & $\begin{array}{c}\text { Strongly } \\
\text { agree }\end{array}$ \\
\hline 1 & 2 & 3 & 4 & 5 & 6 \\
\hline
\end{tabular}

c. Shots would save our community money by preventing serious illnesses if everyone got them.

\begin{tabular}{cccccc}
\hline $\begin{array}{c}\text { Strongly } \\
\text { Disagree }\end{array}$ & Disagree & $\begin{array}{c}\text { Slightly } \\
\text { disagree }\end{array}$ & $\begin{array}{c}\text { Slightly } \\
\text { Agree }\end{array}$ & Agree & $\begin{array}{c}\text { Strongly } \\
\text { agree }\end{array}$ \\
\hline 1 & 2 & 3 & 4 & 5 & 6 \\
\hline
\end{tabular}


9. Barriers in following immunization recommendations: If your child has had some but not had all of the recommended shots please select circle the answer that best describes your beliefs for each of the following:

Access Barriers

a. It is too difficult to get to the doctor's office or clinic for shots.

\begin{tabular}{cccccc}
\hline $\begin{array}{c}\text { Strongly } \\
\text { Disagree }\end{array}$ & Disagree & $\begin{array}{c}\text { Slightly } \\
\text { disagree }\end{array}$ & $\begin{array}{c}\text { Slightly } \\
\text { Agree }\end{array}$ & Agree & $\begin{array}{c}\text { Strongly } \\
\text { agree }\end{array}$ \\
\hline 1 & 2 & 3 & 4 & 5 & 6 \\
\hline
\end{tabular}

b. We can't afford to get all of the shots.

\begin{tabular}{cccccc}
\hline $\begin{array}{c}\text { Strongly } \\
\text { Disagree }\end{array}$ & Disagree & $\begin{array}{c}\text { Slightly } \\
\text { disagree }\end{array}$ & $\begin{array}{c}\text { Slightly } \\
\text { Agree }\end{array}$ & Agree & $\begin{array}{c}\text { Strongly } \\
\text { agree }\end{array}$ \\
\hline 1 & 2 & 3 & 4 & 5 & 6 \\
\hline
\end{tabular}

c. Shots are too expensive

\begin{tabular}{cccccc}
\hline $\begin{array}{c}\text { Strongly } \\
\text { Disagree }\end{array}$ & Disagree & $\begin{array}{c}\text { Slightly } \\
\text { disagree }\end{array}$ & $\begin{array}{c}\text { Slightly } \\
\text { Agree }\end{array}$ & Agree & $\begin{array}{c}\text { Strongly } \\
\text { agree }\end{array}$ \\
\hline 1 & 2 & 3 & 4 & 5 & 6 \\
\hline
\end{tabular}

10. Personal/Philosophical Beliefs

a. There are too many recommended shots.

\begin{tabular}{cccccc}
\hline $\begin{array}{c}\text { Strongly } \\
\text { Disagree }\end{array}$ & Disagree & $\begin{array}{c}\text { Slightly } \\
\text { disagree }\end{array}$ & $\begin{array}{c}\text { Slightly } \\
\text { Agree }\end{array}$ & Agree & $\begin{array}{c}\text { Strongly } \\
\text { agree }\end{array}$ \\
\hline 1 & 2 & 3 & 4 & 5 & 6 \\
\hline
\end{tabular}

b. Giving all of the recommended shots at once is too aggressive (hard on the baby).

\begin{tabular}{cccccc}
\hline $\begin{array}{c}\text { Strongly } \\
\text { Disagree }\end{array}$ & Disagree & $\begin{array}{c}\text { Slightly } \\
\text { disagree }\end{array}$ & $\begin{array}{c}\text { Slightly } \\
\text { Agree }\end{array}$ & Agree & $\begin{array}{c}\text { Strongly } \\
\text { agree }\end{array}$ \\
\hline 1 & 2 & 3 & 4 & 5 & 6 \\
\hline
\end{tabular}

c. I have heard that some of the shots come from aborted babies.

\begin{tabular}{cccccc}
\hline Strongly & Disagree & Slightly & Slightly & Agree & Strongly \\
\hline
\end{tabular}




\begin{tabular}{cccccc}
\hline Disagree & & disagree & Agree & & agree \\
\hline 1 & 2 & 3 & 4 & 5 & 6 \\
\hline
\end{tabular}

d. Babies are too young to handle all of the recommended shots.

\begin{tabular}{cccccc}
\hline $\begin{array}{c}\text { Strongly } \\
\text { Disagree }\end{array}$ & Disagree & $\begin{array}{c}\text { Slightly } \\
\text { disagree }\end{array}$ & $\begin{array}{c}\text { Slightly } \\
\text { Agree }\end{array}$ & Agree & $\begin{array}{c}\text { Strongly } \\
\text { agree }\end{array}$ \\
\hline 1 & 2 & 3 & 4 & 5 & 6 \\
\hline
\end{tabular}

e. The diseases shots prevent are not a problem in our community.

\begin{tabular}{cccccc}
\hline $\begin{array}{c}\text { Strongly } \\
\text { Disagree }\end{array}$ & Disagree & $\begin{array}{c}\text { Slightly } \\
\text { disagree }\end{array}$ & $\begin{array}{c}\text { Slightly } \\
\text { Agree }\end{array}$ & Agree & $\begin{array}{c}\text { Strongly } \\
\text { agree }\end{array}$ \\
\hline 1 & 2 & 3 & 4 & 5 & 6 \\
\hline
\end{tabular}

\section{Safety Concerns}

a. Shots inject children with dangerous germs like Polio or whooping cough.

\begin{tabular}{cccccc}
\hline $\begin{array}{c}\text { Strongly } \\
\text { Disagree }\end{array}$ & Disagree & $\begin{array}{c}\text { Slightly } \\
\text { disagree }\end{array}$ & $\begin{array}{c}\text { Slightly } \\
\text { Agree }\end{array}$ & Agree & $\begin{array}{c}\text { Strongly } \\
\text { agree }\end{array}$ \\
\hline 1 & 2 & 3 & 4 & 5 & 6 \\
\hline
\end{tabular}

b. Shots have too many side effects to be worth the risk of getting them.

\begin{tabular}{cccccc}
\hline $\begin{array}{c}\text { Strongly } \\
\text { Disagree }\end{array}$ & Disagree & $\begin{array}{c}\text { Slightly } \\
\text { disagree }\end{array}$ & $\begin{array}{c}\text { Slightly } \\
\text { Agree }\end{array}$ & Agree & $\begin{array}{c}\text { Strongly } \\
\text { agree }\end{array}$ \\
\hline 1 & 2 & 3 & 4 & 5 & 6 \\
\hline
\end{tabular}

c. I have heard that some shots have dangerous preservative of chemicals in them.

\begin{tabular}{cccccc}
\hline $\begin{array}{c}\text { Strongly } \\
\text { Disagree }\end{array}$ & Disagree & $\begin{array}{c}\text { Slightly } \\
\text { disagree }\end{array}$ & $\begin{array}{c}\text { Slightly } \\
\text { Agree }\end{array}$ & Agree & $\begin{array}{c}\text { Strongly } \\
\text { agree }\end{array}$ \\
\hline 1 & 2 & 3 & 4 & 5 & 6 \\
\hline
\end{tabular}

d. Shots can cause high fevers more than one week after they are given.

\begin{tabular}{cccccc}
\hline $\begin{array}{c}\text { Strongly } \\
\text { Disagree }\end{array}$ & Disagree & $\begin{array}{c}\text { Slightly } \\
\text { disagree }\end{array}$ & $\begin{array}{c}\text { Slightly } \\
\text { Agree }\end{array}$ & Agree & $\begin{array}{c}\text { Strongly } \\
\text { agree }\end{array}$ \\
\hline 1 & 2 & 3 & 4 & 5 & 6 \\
\hline
\end{tabular}

e. Shots can cause too much stress on the system if given all at once. 


\begin{tabular}{cccccc}
\hline $\begin{array}{c}\text { Strongly } \\
\text { Disagree }\end{array}$ & Disagree & $\begin{array}{c}\text { Slightly } \\
\text { disagree }\end{array}$ & $\begin{array}{c}\text { Slightly } \\
\text { Agree }\end{array}$ & Agree & $\begin{array}{c}\text { Strongly } \\
\text { agree }\end{array}$ \\
\hline 1 & 2 & 3 & 4 & 5 & 6 \\
\hline
\end{tabular}

f. Shots can cause brain damage.

\begin{tabular}{cccccc}
\hline $\begin{array}{c}\text { Strongly } \\
\text { Disagree }\end{array}$ & Disagree & $\begin{array}{c}\text { Slightly } \\
\text { disagree }\end{array}$ & $\begin{array}{c}\text { Slightly } \\
\text { Agree }\end{array}$ & Agree & $\begin{array}{c}\text { Strongly } \\
\text { agree }\end{array}$ \\
\hline 1 & 2 & 3 & 4 & 5 & 6 \\
\hline
\end{tabular}

g. Shots can cause seizures more than one week after they are given.

\begin{tabular}{cccccc}
\hline $\begin{array}{c}\text { Strongly } \\
\text { Disagree }\end{array}$ & Disagree & $\begin{array}{c}\text { Slightly } \\
\text { disagree }\end{array}$ & $\begin{array}{c}\text { Slightly } \\
\text { Agree }\end{array}$ & Agree & $\begin{array}{c}\text { Strongly } \\
\text { agree }\end{array}$ \\
\hline 1 & 2 & 3 & 4 & 5 & 6 \\
\hline
\end{tabular}

12. If you give your children all baby shots, please circle the answer that best describes your beliefs about each of the following statements:

a. Shots are protective against diseases.

\begin{tabular}{cccccc}
\hline $\begin{array}{c}\text { Strongly } \\
\text { Disagree }\end{array}$ & Disagree & $\begin{array}{c}\text { Slightly } \\
\text { disagree }\end{array}$ & $\begin{array}{c}\text { Slightly } \\
\text { Agree }\end{array}$ & Agree & $\begin{array}{c}\text { Strongly } \\
\text { agree }\end{array}$ \\
\hline 1 & 2 & 3 & 4 & 5 & 6 \\
\hline
\end{tabular}

b. My doctor/nurse recommends them.

\begin{tabular}{cccccc}
\hline $\begin{array}{c}\text { Strongly } \\
\text { Disagree }\end{array}$ & Disagree & $\begin{array}{c}\text { Slightly } \\
\text { disagree }\end{array}$ & $\begin{array}{c}\text { Slightly } \\
\text { Agree }\end{array}$ & Agree & $\begin{array}{c}\text { Strongly } \\
\text { agree }\end{array}$ \\
\hline 1 & 2 & 3 & 4 & 5 & 6 \\
\hline
\end{tabular}

c. Shots are safer overall than the diseases children would get without shots.

\begin{tabular}{cccccc}
\hline $\begin{array}{c}\text { Strongly } \\
\text { Disagree }\end{array}$ & Disagree & $\begin{array}{c}\text { Slightly } \\
\text { disagree }\end{array}$ & $\begin{array}{c}\text { Slightly } \\
\text { Agree }\end{array}$ & Agree & $\begin{array}{c}\text { Strongly } \\
\text { agree }\end{array}$ \\
\hline 1 & 2 & 3 & 4 & 5 & 6 \\
\hline
\end{tabular}

d. Not having my child immunized could contribute to a vaccine preventable disease in my community.

\begin{tabular}{cccccc}
\hline $\begin{array}{c}\text { Strongly } \\
\text { Disagree }\end{array}$ & Disagree & $\begin{array}{c}\text { Slightly } \\
\text { disagree }\end{array}$ & $\begin{array}{c}\text { Slightly } \\
\text { Agree }\end{array}$ & Agree & $\begin{array}{c}\text { Strongly } \\
\text { agree }\end{array}$ \\
\hline 1 & 2 & 3 & 4 & 5 & 6 \\
\hline
\end{tabular}


13. My doctor/nurse wants to give shots at 2, 4, and 6 months of age. Do you believe this is too early?

1. Yes

2. No

14. If you do not get baby shots for your children, circle any of the following that would change your mind. I would change my mind if:

a. My bishop/elder recommended them.

\begin{tabular}{cccccc}
\hline $\begin{array}{c}\text { Strongly } \\
\text { Disagree }\end{array}$ & Disagree & $\begin{array}{c}\text { Slightly } \\
\text { disagree }\end{array}$ & $\begin{array}{c}\text { Slightly } \\
\text { Agree }\end{array}$ & Agree & $\begin{array}{c}\text { Strongly } \\
\text { agree }\end{array}$ \\
\hline 1 & 2 & 3 & 4 & 5 & 6 \\
\hline
\end{tabular}

b. My parents /family encouraged them.

\begin{tabular}{cccccc}
\hline $\begin{array}{c}\text { Strongly } \\
\text { Disagree }\end{array}$ & Disagree & $\begin{array}{c}\text { Slightly } \\
\text { disagree }\end{array}$ & $\begin{array}{c}\text { Slightly } \\
\text { Agree }\end{array}$ & Agree & $\begin{array}{c}\text { Strongly } \\
\text { agree }\end{array}$ \\
\hline 1 & 2 & 3 & 4 & 5 & 6 \\
\hline
\end{tabular}

c. Other Amish families I know got them.

\begin{tabular}{cccccc}
\hline $\begin{array}{c}\text { Strongly } \\
\text { Disagree }\end{array}$ & Disagree & $\begin{array}{c}\text { Slightly } \\
\text { disagree }\end{array}$ & $\begin{array}{c}\text { Slightly } \\
\text { Agree }\end{array}$ & Agree & $\begin{array}{c}\text { Strongly } \\
\text { agree }\end{array}$ \\
\hline 1 & 2 & 3 & 4 & 5 & 6 \\
\hline
\end{tabular}

d. The shots were cheaper.

\begin{tabular}{cccccc}
\hline $\begin{array}{c}\text { Strongly } \\
\text { Disagree }\end{array}$ & Disagree & $\begin{array}{c}\text { Slightly } \\
\text { disagree }\end{array}$ & $\begin{array}{c}\text { Slightly } \\
\text { Agree }\end{array}$ & Agree & $\begin{array}{c}\text { Strongly } \\
\text { agree }\end{array}$ \\
\hline 1 & 2 & 3 & 4 & 5 & 6 \\
\hline
\end{tabular}

e. It were easier to get the doctor's office/clinic.

\begin{tabular}{cccccc}
\hline $\begin{array}{c}\text { Strongly } \\
\text { Disagree }\end{array}$ & Disagree & $\begin{array}{c}\text { Slightly } \\
\text { disagree }\end{array}$ & $\begin{array}{c}\text { Slightly } \\
\text { Agree }\end{array}$ & Agree & $\begin{array}{c}\text { Strongly } \\
\text { agree }\end{array}$ \\
\hline 1 & 2 & 3 & 4 & 5 & 6 \\
\hline
\end{tabular}

f. There were a disease outbreak.

\begin{tabular}{llcccc}
\hline $\begin{array}{l}\text { Strongly } \\
\text { Disagree }\end{array}$ & Disagree & $\begin{array}{c}\text { Slightly } \\
\text { disagree }\end{array}$ & $\begin{array}{c}\text { Slightly } \\
\text { Agree }\end{array}$ & Agree & $\begin{array}{c}\text { Strongly } \\
\text { agree }\end{array}$ \\
\hline
\end{tabular}




\begin{tabular}{llllll}
\hline 1 & 2 & 3 & 4 & 5 & 6 \\
\hline
\end{tabular}

g. I knew the shots were safe to give.

\begin{tabular}{cccccc}
\hline $\begin{array}{c}\text { Strongly } \\
\text { Disagree }\end{array}$ & Disagree & $\begin{array}{c}\text { Slightly } \\
\text { disagree }\end{array}$ & $\begin{array}{c}\text { Slightly } \\
\text { Agree }\end{array}$ & Agree & $\begin{array}{c}\text { Strongly } \\
\text { agree }\end{array}$ \\
\hline 1 & 2 & 3 & 4 & 5 & 6 \\
\hline
\end{tabular}

h. Shots were required by the law/government.

\begin{tabular}{cccccc}
\hline $\begin{array}{c}\text { Strongly } \\
\text { Disagree }\end{array}$ & Disagree & $\begin{array}{c}\text { Slightly } \\
\text { disagree }\end{array}$ & $\begin{array}{c}\text { Slightly } \\
\text { Agree }\end{array}$ & Agree & $\begin{array}{c}\text { Strongly } \\
\text { agree }\end{array}$ \\
\hline 1 & 2 & 3 & 4 & 5 & 6 \\
\hline
\end{tabular}

15. Do you personally know anyone who has had a bad reaction/side effect from a baby shot?

1. Yes

2. No

16. Did you know that the Department of Health in Ashtabula County offers immunizations clinics throughout the county?

1. Yes

2. No

17. Did you know that you do not need to pay for shots from the Health Department?

1. Yes

2. No

18. Please indicate where you have received information about childhood shots.

1. School

2. My doctor/nurse

3. My chiropractor

4. My family 
5. My midwife

6. Articles in magazines and papers

19. If you have been advised against getting childhood shots, who give you this advice? Please indicate all that apply.

1. My minister/bishop

2. My midwife

3. My parents or other family

4. My doctor/nurse

5. Books/articles I have read

6. My chiropractor

7. Friends or members of my community

20. Not having my child immunized according to the recommended schedule contributed to a vaccine preventable disease outbreak in my community.

1. Yes

2. No 


\section{Appendix B: 2014 CDC Recommended Immunization Schedule}

Figure 1. Recommended immunization schedule for persons aged 0 through 18 years -2013 .

(FORTHOSE WHO FALL BEHIND OR START LATE, SEE THECATCH-UP SCHEDULE[FIGURE 2]).

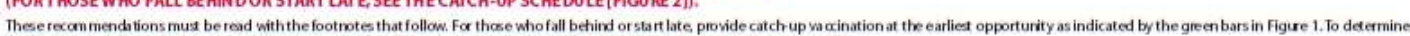

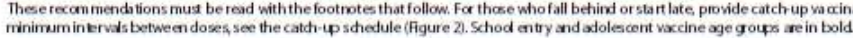

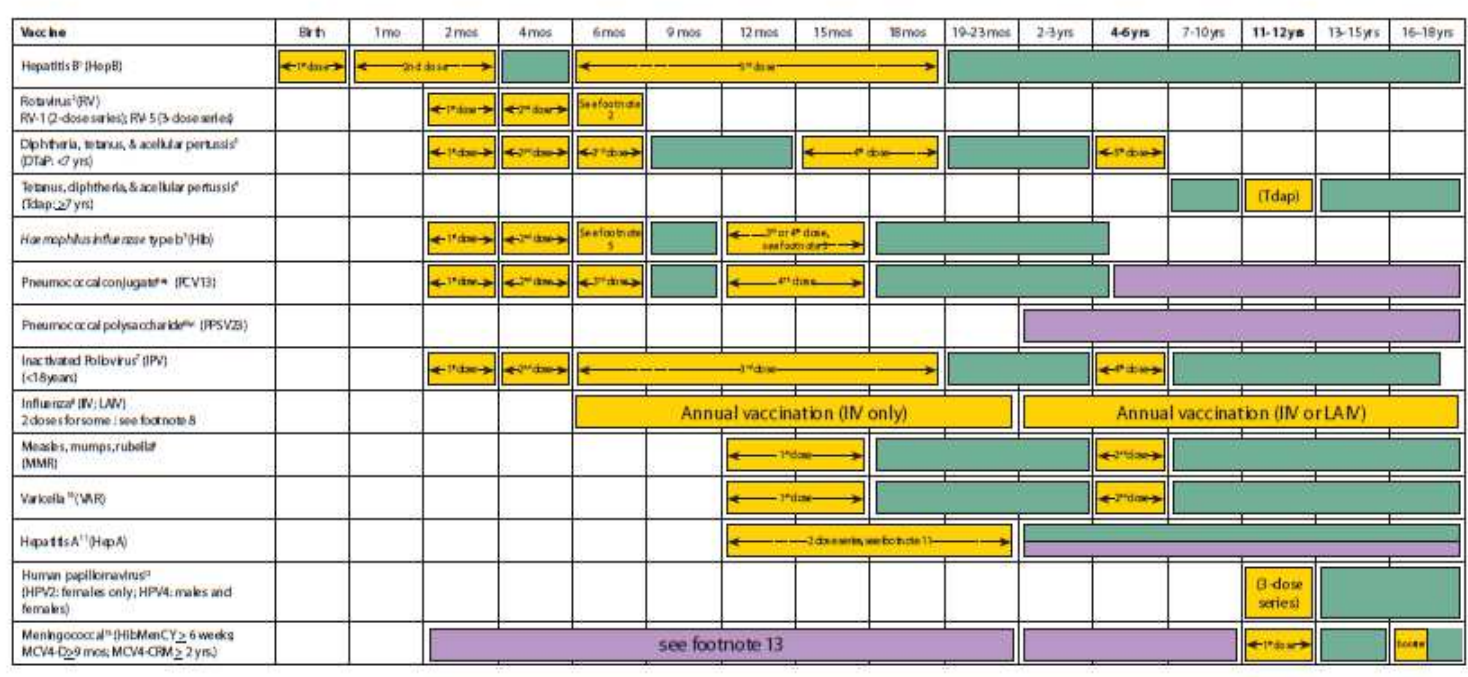

$$
\text { Mageforail chidinen }
$$

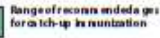

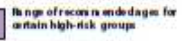

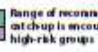

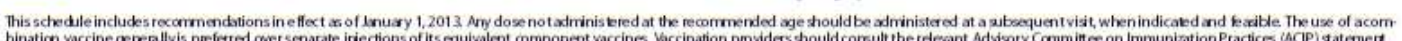

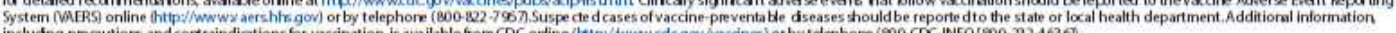
including precaut wis

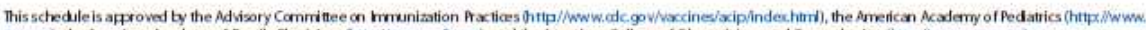

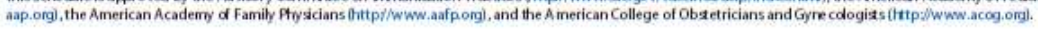

NOTE: The above recommendations must be read along with the footnotes of this schedule. 
$12 / 5 / 13$

Appendix C: Permission to Use Instrument

\section{Hi Chris}

You can use this instrument on one condition- that you come visit me sometime this year and talk to me about how the study is going.

It sounds great, and I am excited to support it in any way I can, I am working fulltime at a clinic in Mount Eaton, OH (Wayne County), where we focus on the inherited disorders of the Amish. We stock, immunizations through Vaccines for Children. I really enjoy talking to parents about vaccines, and I am still learning about how they perceive them.

\section{Olivia}

Olivia Wenger, MD

New Leaf Clinic for Special Children 15988 East Chestnut St.

Mount Eaton, OH 44659

Phone (330) 359-9888 


\section{Appendix D: Descriptive Statistics}

Descriptive Statistics of Participants' Knowledge, Belief, Attitudes, and Opinions of Childhood Immunization by Whether they Provided Shots on Schedule and Gender

\begin{tabular}{|c|c|c|c|c|c|c|c|}
\hline Variable & $n$ & Min & Max & Mean & $\begin{array}{c}\text { Std. } \\
\text { Deviation }\end{array}$ & Skewness & Kurtosis \\
\hline \multicolumn{8}{|c|}{ All Shots on Schedule } \\
\hline \multicolumn{8}{|c|}{ Male } \\
\hline Knowledge & 4 & 4.600 & 5.130 & 4.850 & 0.290 & 0.046 & -5.737 \\
\hline Belief & 4 & 3.200 & 5.000 & 4.150 & 0.985 & -0.036 & -5.795 \\
\hline Attitude & 4 & 1.000 & 3.000 & 1.950 & 0.823 & 0.356 & 1.282 \\
\hline Opinion & 4 & 4.670 & 5.000 & 4.917 & 0.167 & -2.000 & 4.000 \\
\hline \multicolumn{8}{|l|}{ Female } \\
\hline Knowledge & 28 & 4.270 & 6.000 & 5.074 & 0.563 & 0.418 & -1.131 \\
\hline Belief & 28 & 2.600 & 6.000 & 4.164 & 0.904 & 0.503 & -0.060 \\
\hline Attitude & 28 & 1.000 & 3.400 & 2.393 & 0.593 & -0.266 & -0.492 \\
\hline Opinion & 28 & 4.000 & 6.000 & 4.869 & 0.532 & 0.350 & 0.188 \\
\hline \multicolumn{8}{|c|}{ Some/No Shots on Schedule } \\
\hline \multicolumn{8}{|c|}{ Male } \\
\hline Knowledge & 1 & 4.670 & 4.670 & 4.667 & N/A & N/A & N/A \\
\hline Belief & 1 & 3.400 & 3.400 & 3.400 & N/A & N/A & $\mathrm{N} / \mathrm{A}$ \\
\hline Attitude & 1 & 2.200 & 2.200 & 2.200 & $\mathrm{~N} / \mathrm{A}$ & $\mathrm{N} / \mathrm{A}$ & $\mathrm{N} / \mathrm{A}$ \\
\hline Opinion & 1 & 5.000 & 5.000 & 5.000 & N/A & N/A & N/A \\
\hline \multicolumn{8}{|l|}{ Female } \\
\hline Knowledge & 20 & 3.400 & 5.530 & 4.470 & 0.565 & -0.446 & 0.072 \\
\hline Belief & 20 & 1.600 & 4.800 & 3.580 & 0.865 & -0.734 & 0.201 \\
\hline Attitude & 20 & 1.000 & 4.400 & 2.410 & 0.697 & 0.873 & 2.911 \\
\hline Opinion & 20 & 2.000 & 5.330 & 4.317 & 1.172 & -1.350 & 0.132 \\
\hline
\end{tabular}

\section{Kruskal-Wallis Tests}

Summary Statistics of Kruskal-Wallis Tests Conducted for Research Questions 1-3

\begin{tabular}{|c|c|c|c|}
\hline Research Question & $\chi^{2}$ & $\mathrm{df}$ & Sig. $(p)$ \\
\hline RQ1 & 0.608 & 1 & 0.435 \\
\hline RQ2 & 0.485 & 1 & 0.486 \\
\hline RQ3 & 0.415 & 1 & 0.519 \\
\hline
\end{tabular}


Model Summary of the Tests of Between-subjects Effects for Hypothesis 2

\begin{tabular}{|c|c|c|c|c|c|c|}
\hline Dependent Variable & $\begin{array}{l}\text { Type III Sum } \\
\text { of Squares }\end{array}$ & $\mathrm{df}$ & $\begin{array}{l}\text { Mean } \\
\text { Square }\end{array}$ & $\mathrm{F}$ & Sig. $(p)$ & $\begin{array}{c}\text { Partial Eta } \\
\text { Squared }\end{array}$ \\
\hline \multicolumn{7}{|l|}{ Corrected Model } \\
\hline Knowledge & 4.166 & 3 & 1.389 & 4.538 & 0.007 & 0.217 \\
\hline Belief & 6.049 & 3 & 2.016 & 2.625 & 0.061 & 0.138 \\
\hline Attitude & 1.409 & 3 & 0.470 & 1.144 & 0.341 & 0.065 \\
\hline Opinion & 4.401 & 3 & 1.467 & 2.154 & 0.105 & 0.117 \\
\hline \multicolumn{7}{|l|}{ Intercept } \\
\hline Knowledge & 540.851 & 1 & 540.851 & 1767.254 & $<.001$ & 0.973 \\
\hline Belief & 386.167 & 1 & 386.167 & 502.739 & $<.001$ & 0.911 \\
\hline Attitude & 131.282 & 1 & 131.282 & 319.789 & $<.001$ & 0.867 \\
\hline Opinion & 520.310 & 1 & 520.310 & 763.872 & $<.001$ & 0.940 \\
\hline \multicolumn{7}{|l|}{ Shots on Schedule * Age } \\
\hline Knowledge & 0.098 & 1 & 0.098 & 0.320 & 0.574 & 0.006 \\
\hline Belief & 0.940 & 1 & 0.940 & 1.224 & 0.274 & 0.024 \\
\hline Attitude & 0.407 & 1 & 0.407 & 0.991 & 0.324 & 0.020 \\
\hline Opinion & 0.839 & 1 & 0.839 & 1.231 & 0.273 & 0.025 \\
\hline \multicolumn{7}{|l|}{ Error } \\
\hline Knowledge & 14.996 & 49 & 0.306 & & & \\
\hline Belief & 37.638 & 49 & 0.768 & & & \\
\hline Attitude & 20.116 & 49 & 0.411 & & & \\
\hline Opinion & 33.376 & 49 & 0.681 & & & \\
\hline \multicolumn{7}{|l|}{ Total } \\
\hline Knowledge & 1251.187 & 53 & & & & \\
\hline Belief & 861.560 & 53 & & & & \\
\hline Attitude & 317.280 & 53 & & & & \\
\hline Opinion & 1192.000 & 53 & & & & \\
\hline \multicolumn{7}{|l|}{ Corrected Total } \\
\hline Knowledge & 19.162 & 52 & & & & \\
\hline Belief & 43.688 & 52 & & & & \\
\hline Attitude & 21.525 & 52 & & & & \\
\hline Opinion & 37.778 & 52 & & & & \\
\hline
\end{tabular}

Note. Dependent variables $=$ knowledge, belief, attitudes, and opinions; total $N=53$ 
Model Summary of the Tests of Between-subjects Effects for Hypothesis 3

\begin{tabular}{|c|c|c|c|c|c|c|}
\hline Dependent Variable & $\begin{array}{l}\text { Type III Sum } \\
\text { of Squares }\end{array}$ & $\mathrm{df}$ & $\begin{array}{c}\text { Mean } \\
\text { Square }\end{array}$ & $\mathrm{F}$ & Sig. $(p)$ & $\begin{array}{c}\text { Partial Eta } \\
\text { Squared }\end{array}$ \\
\hline \multicolumn{7}{|l|}{ Corrected Model } \\
\hline Knowledge & 4.281 & 3 & 1.427 & 4.698 & 0.006 & 0.223 \\
\hline Belief & 4.461 & 3 & 1.487 & 1.858 & 0.149 & 0.102 \\
\hline Attitude & 0.778 & 3 & 0.259 & 0.612 & 0.610 & 0.036 \\
\hline Opinion & 3.958 & 3 & 1.319 & 1.911 & 0.140 & 0.105 \\
\hline \multicolumn{7}{|l|}{ Intercept } \\
\hline Knowledge & 271.991 & 1 & 271.991 & 895.567 & $<.001$ & 0.948 \\
\hline Belief & 175.124 & 1 & 175.124 & 218.758 & $<.001$ & 0.817 \\
\hline Attitude & 60.008 & 1 & 60.008 & 141.729 & $<.001$ & 0.743 \\
\hline Opinion & 273.188 & 1 & 273.188 & 395.809 & $<.001$ & 0.890 \\
\hline \multicolumn{7}{|c|}{ Shots on Schedule * Gender } \\
\hline Knowledge & 0.132 & 1 & 0.132 & 0.436 & 0.512 & 0.009 \\
\hline Belief & 0.021 & 1 & 0.021 & 0.026 & 0.873 & 0.001 \\
\hline Attitude & 0.041 & 1 & 0.041 & 0.096 & 0.758 & 0.002 \\
\hline Opinion & 0.303 & 1 & 0.303 & 0.438 & 0.511 & 0.009 \\
\hline \multicolumn{7}{|l|}{ Error } \\
\hline Knowledge & 14.882 & 49 & 0.304 & & & \\
\hline Belief & 39.226 & 49 & 0.801 & & & \\
\hline Attitude & 20.747 & 49 & 0.423 & & & \\
\hline Opinion & 33.820 & 49 & 0.690 & & & \\
\hline \multicolumn{7}{|l|}{ Total } \\
\hline Knowledge & 1251.187 & 53 & & & & \\
\hline Belief & 861.560 & 53 & & & & \\
\hline Attitude & 317.280 & 53 & & & & \\
\hline Opinion & 1192.000 & 53 & & & & \\
\hline \multicolumn{7}{|l|}{ Corrected Total } \\
\hline Knowledge & 19.162 & 52 & & & & \\
\hline Belief & 43.688 & 52 & & & & \\
\hline Attitude & 21.525 & 52 & & & & \\
\hline Opinion & 37.778 & 52 & & & & \\
\hline
\end{tabular}

Statistics $\left(5^{\text {th }}\right.$ edition). Boston, MA: Pearson.

Figure 2 
Mean Plots

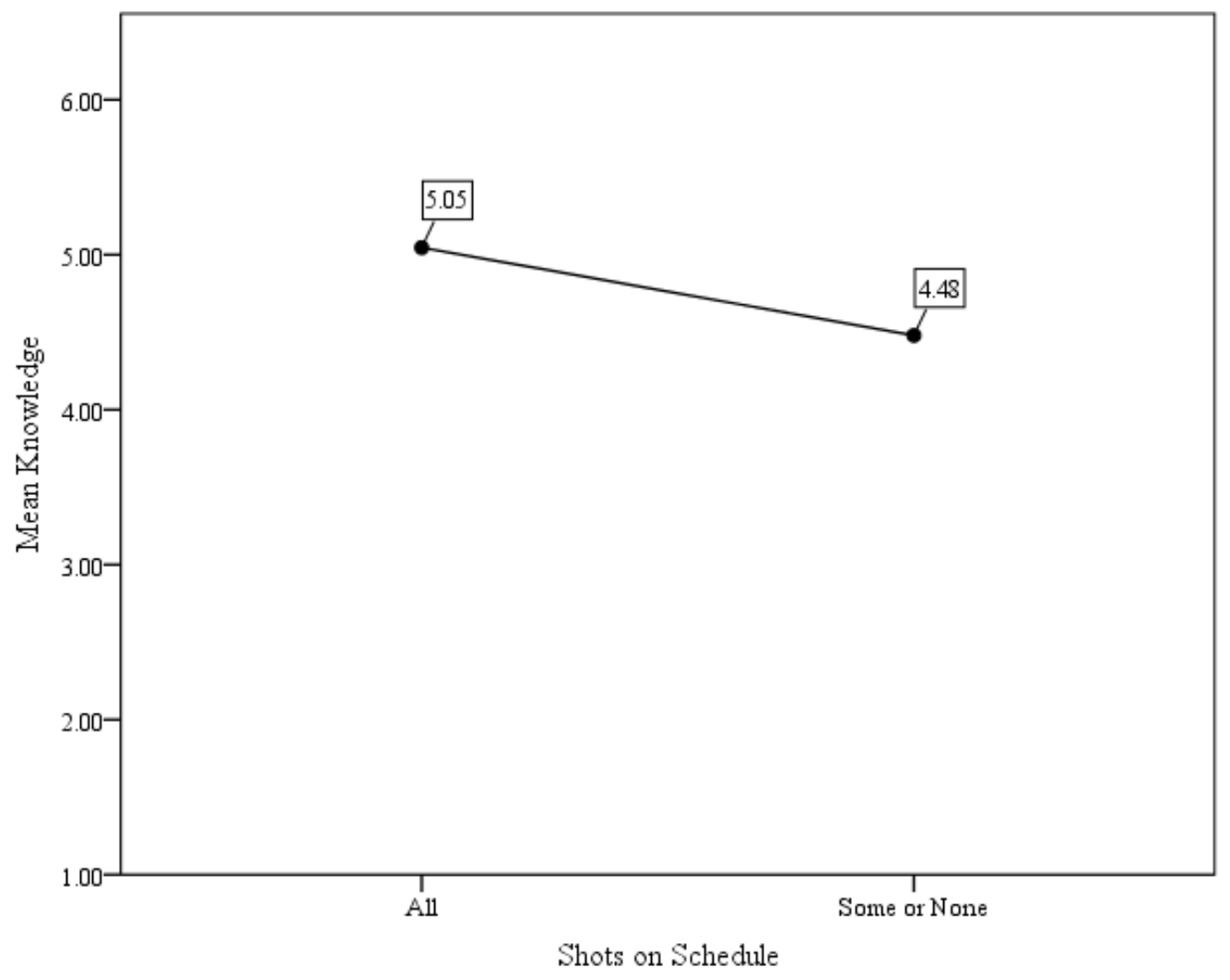

Means plot of participants' knowledge toward childhood immunization scores by whether they provided shots on time 


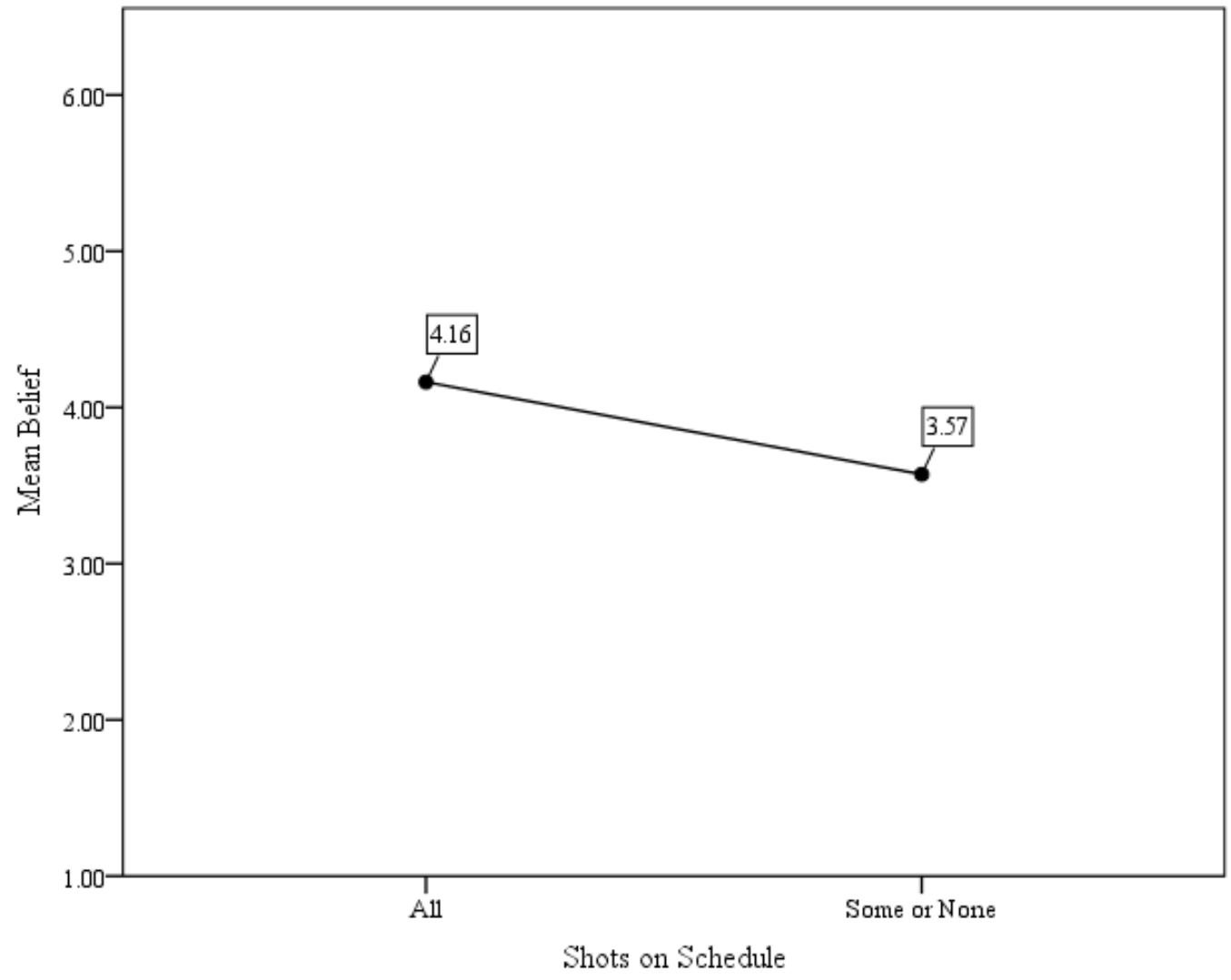

Means plot of participants' beliefs toward childhood immunization scores by whether they provided shots on time 


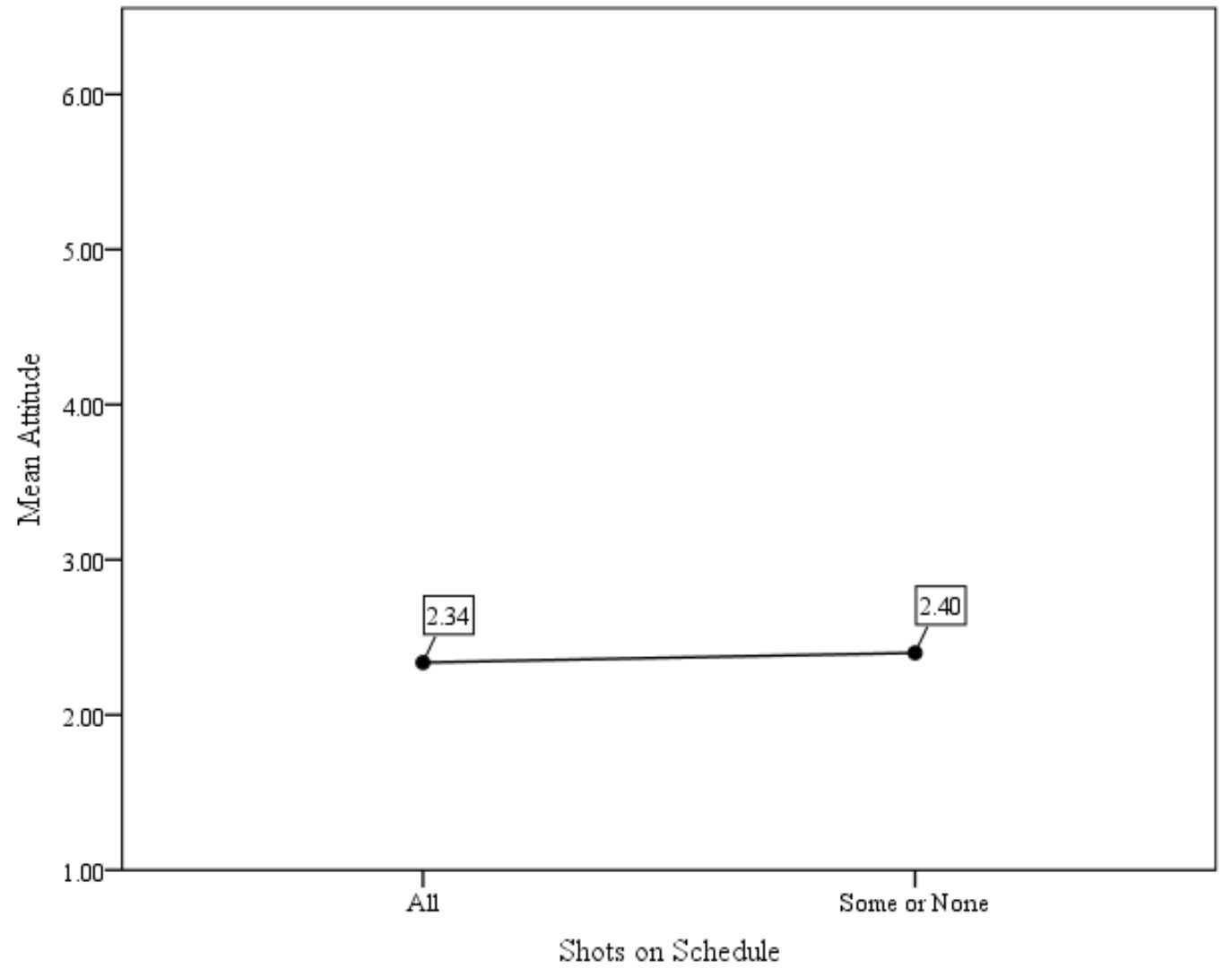

Means plot of participants' attitudes toward childhood immunization scores by whether they provided shots on time 


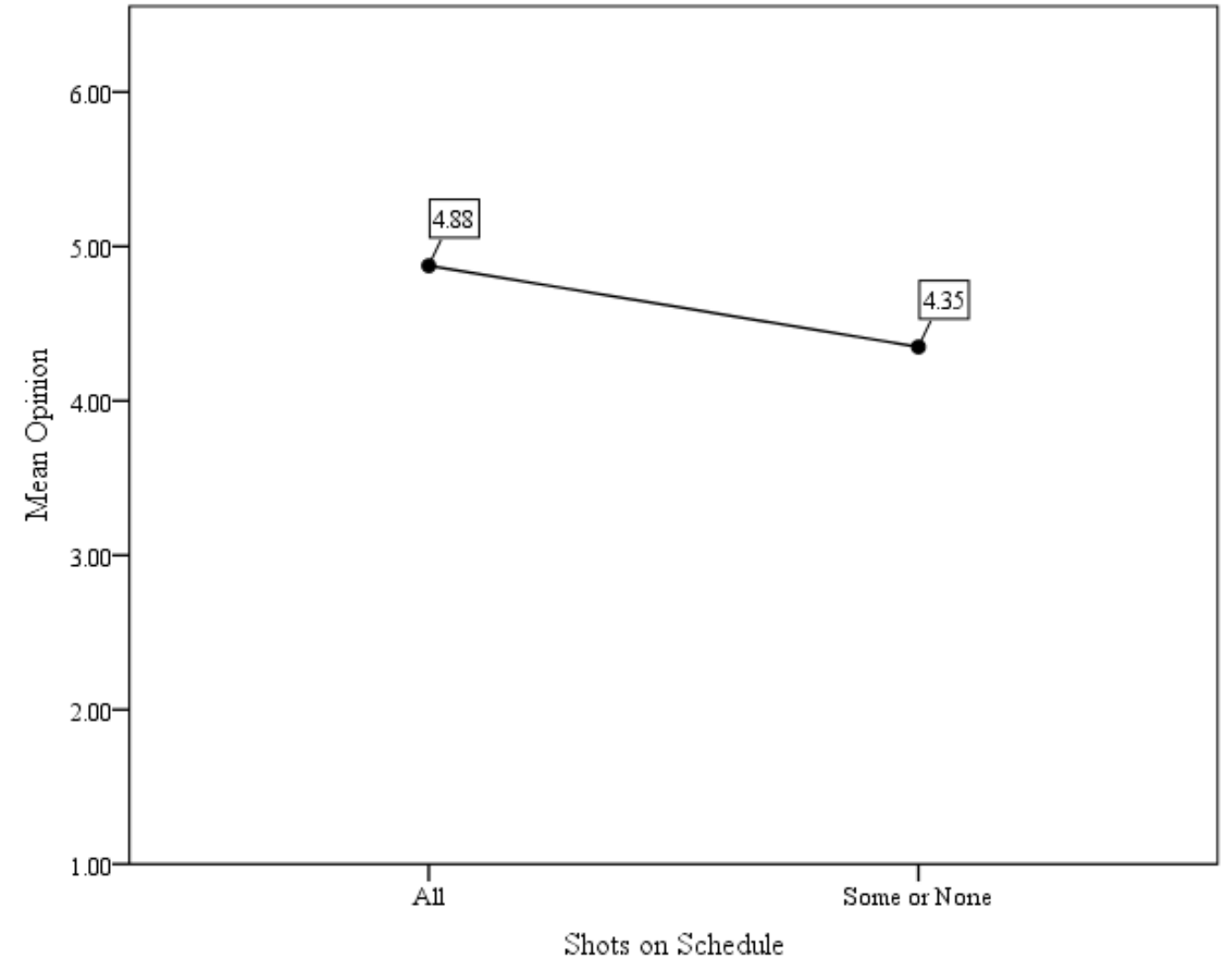

Means plot of participants' opinions toward childhood immunization scores by whether they provided shots on time 